\title{
A Multiscale Assessment of the Risks Imposed by Plantation Forestry on Plant Biodiversity in the Hotspot Central Chile
}

\author{
Andreas Ch. Braun ${ }^{1}$, Joachim Vogt ${ }^{2}$ \\ ${ }^{1}$ Chair of Remote Sensing and Landscape Information Systems (FeLis), University of Freiburg, Freiburg im \\ Breisgau, Germany \\ ${ }^{2}$ Institute of Regional Science (IfR), Karlsruhe Institute of Technology (KIT), Karlsruhe, Germany \\ Email: andreas.braun@felis.uni-freiburg.de, vogt@kit.edu
}

Received 7 November 2014; revised 6 December 2014; accepted 18 December 2014

Academic Editor: Victor R. Savage, National University of Singapore, Singapore

Copyright (C) 2014 by authors and Scientific Research Publishing Inc.

This work is licensed under the Creative Commons Attribution International License (CC BY). http://creativecommons.org/licenses/by/4.0/

(c) (i) Open Access

\section{Abstract}

We assessed the effects of plantations of exotic trees (Pinus radiata, Eucalyptus globulus, and Populus nigra) on plant biodiversity in the temperate zone of the biodiversity hotspot of Central Chile. This region has suffered from intense deforestation in favor of plantation establishment in the major part of the coastal area since the neoliberal turn in 1973. The approach presented aimed to analyze plant biodiversity on the $\alpha$-, $\beta$ - and $\gamma$-scale. Furthermore, a plantation evaluation index was applied in order to provide quantitative figures on management practices. Species richness is reduced by $50 \%$ below plantations. Diversity and evenness index values are also significantly reduced. Analyses on $\beta$-similarity indicate that plantations do not host species absent in adjacent native forests, and no additional habitat heterogeneity is gained. On the $\gamma$-scale, plantations lower the number of total species observed; especially of endemic species. The abundance of species considered as invasive is significantly higher and frequently, invasive plants dominate the understory. The evaluation index attests rather poor plantation management in Central Chile since plantations are grown as monocultures, natural elements and native species are lacking at specific sites and plantations are insufficiently connected to native plant formations at the landscape scale. Results give much concern since deforestation processes as observed in our study area is about to begin in Patagonia as well. If management practices from the temperate zone are adopted in Patagonia, a considerable decline in plant biodiversity has to be expected there.

\section{Keywords}

Biodiversity Decline, Plantations, Biodiversity Hotspot, Pinus radiate, Eucalyptus globules, Chile 


\section{Introduction}

Deforestation is reported to cause rapid and significant losses in biodiversity and extinction of endemic species worldwide [1]-[5]. Biodiversity decline can be caused by direct removal of habitat and local extinction or by habitat fragmentation. However, secondary effects that arise e.g. from the construction of roads can have much stronger impacts on biodiversity [6]-[8]. Central Chile is considered a biodiversity hotspot, not only because of its total species richness, but due to its high level of endemism [9]. The coastal area of the temperate zone of Central Chile has been altered by a rapid, intense and widespread process of transformation. The transformation from Mediterranean temperate shrublands and forests to exotic tree plantations causes rapid deforestation and forest fragmentation [10]-[16]. After the neoliberal turn in 1973, the Chilean government forcefully promoted forestry with exotic tree species_-mainly Pinus radiata and Eucalyptus globulus [17]-[20]. Between 1973 and $2000,67 \%$ of the original extent of temperate forests was lost [10]. Although some further minor drivers have been identified, deforestation has largely been attributed to replacement with exotic plantations [11] [18] [21]-[24]. Until today, plantations with exotic tree species continue to spread in the temperate zone of Chile leaving less than $4 \%$ of the area covered with native forests (own data, unpublished results). Of these remaining forest patches, over $60 \%$ are smaller than 1 ha [25]. Since native forest sites available for plantation establishment are almost depleted, forest companies have recently started to establish plantations in Patagonia [26] [27]. Due to the insufficient conservation strategies in Chile, this process gives much concern [15] [20] [28]. Chilean natural parks and reserves (NPR) cover a relatively large portion of the country (19\% of the country's area). Despite this large spatial extent, the Chilean system of NPRs is considered rather inefficient, although improvements by appropriate funding could theoretically be realized by the Chilean government [29]. 90\% of the NPRs are found in zones with low plant biodiversity and in areas of rather low economic interest for forest companies [20] [21]. Hence, it seems unlikely that the biodiversity hotspots of Central Chile or Patagonia can be conserved with existing instruments.

The motivation of this report is as follows: Central Chile-like all other biodiversity hotspots-is considered a priority region for environmental conservation [9]. When discussing conservation strategies, one has to decide what to conserve-landscapes, ecosystems, communities, populations or species [30]. In Central Chile, native forest ecosystems are rapidly replaced by exotic tree plantations. Thus, a rapid deforestation and forest fragmentation have been observed, which can principally, although not exclusively be attributed to plantation establishment [10] [14]. Although small remnants are left in between plantations, alternative habitats are hardly being created. Hence, obviously larger units (like entire landscapes or ecosystems) are currently not being conserved, which raises the importance of least conserving the species typical for these units. Such a conservation strategy requires alternative habitats for species in the modified landscapes. This implies that Chilean species need to be able to prevail below the canopy of plantations. If this would be the case, e.g. endemism rates in plantations should be similar to those found in native forests. Furthermore, the $\beta$-diversity between native forests and plantations should be high. There is another opportunity for survival of the Chilean endemics in plantations. Despite local extinction of individual populations, endemics could survive via their metapopulations ${ }^{1}$. For this opportunity, the connectivity of the landscape presence of suitable stepping stone habitats is crucial [31] [32]. Furthermore, species following this survival strategy face a number of constraints (e.g. an effective reproduction mechanism over relatively large distances). These theoretical mechanisms of survival are to be clarified empirically within this report. Therefore, a mainly descriptive approach is followed at first.

Since many studies on deforestation and biodiversity have been published in literature over recent years, the question is, what makes the Chilean case so relevant? Why is Chile not merely a special case of some general concept? First of all, deforestation in Chile is mainly caused by plantation establishment, and not by other land use change processes like e.g. agricultural expansion. Thus, closed canopy tree ecosystems (forests) are replaced by other closed canopy tree ecosystems (plantations). Especially for this situation, our understanding of the influence deforestation on native (plant) biodiversity is limited [33] [34]. While some authors tend to attribute positive effects of plantation establishment on biodiversity - e.g. by diversification of the landscape-[35]-[39],

\footnotetext{
${ }^{1}$ Note that this study does not analyse metapopulations explicitly (e.g. by presenting data on connectivity, dispersal rates, source and sink populations). Nonetheless, for two reasons, it is important to incorporate the notion of metapopulations in the argumentation presented herein. Firstly, it has to be kept in mind that while local extinctions of species may occur which alter $\alpha$-diversity, species may still survive at larger scales (e.g. at the $\gamma$-scale or even higher scales). Thus, the proof of absence of a species in a certain plant formation may not be mistaken as a proof for its total extinction. Secondly, in order to have species survive via such a rescue effect by metapopulations, a certain connectivity between local populations is crucial. Exactly this connectivity is reduced by plantation establishment, c.f. [10]. Both aspects need to be kept in mind when drawing conclusion on Chilean plantation forestry discussed herein.
} 
others focus on negative impacts especially for Chile [11] [20] [27] [40], but also worldwide [41]-[45]. Since plantations grow fast and cover a vast area in Central Chile, this region can be considered a large-scale experiment to study their relationship with biodiversity. Despite the vast distribution of exotic tree plantations, few studies have investigated their effects on biodiversity so far [11] [27].

The main goal of this study is to close existing research gaps by analyzing plant biodiversity in plantations and comparing them to other ecosystems. Some studies by other authors complement our approach. [11] [28] analyze species richness in temperate plant formations, predicting partial declines in species richness for the future. However, plantations are not incorporated into the analysis. [27] compares biodiversity between native forests and plantations on three taxa. The authors find biodiversity in plantations significantly reduced. However, their study analyses the situation in Patagonia and not in central Chile. [39] [46] point out that diversity of the avifauna may be increased within plantations. Yet if plantations are not managed sustainably, the diversity of the avifauna may be reduced as well [47]. [48] points out that the diversity of small mammals is reduced in plantations in contrast to near-natural forests. [49] shows that a reduction of patch size due to forest fragmentation may reduce beetles diversity. [50] sees the habitat of Chilean amphibians endangered by plantation growth, albeit not providing any biodiversity data. Many of these studies focus on the effects of forest fragmentation on biodiversity instead of focusing on biodiversity conditions within plantations themselves. Secondly, with up to $8.15 \%$ of local annual loss, the deforestation rates reported for Central Chile are among the highest worldwide [14]. If deforestation in favor of plantations continues at these rates, biodiversity in plantations should be managed in a sustainable manner [51]. Otherwise, Central Chile will not qualify as a biodiversity hotspot in the future anymore. Thirdly, the same process of deforestation and plantation establishment is about to begin in Chilean Patagonia [26] [27]—a landscape appreciated for its originality. Lastly, plantation establishment is frequently described in an economically biased and ecologically rather optimist perspective [52]. Given the spatial extent of plantation establishment in Chile, though, it is worthwhile to question this position by having a close look on its ecological impacts. Within this report, results on $\alpha$-, $\beta$ - and $\gamma$-diversity will be presented to revise this perspective.

The analysis of the impacts of current management practices (huge monotypic tree cohorts, harvesting by clear felling followed by pesticide applications and fire clearance of the soils) on plant biodiversity in Central Chile will finally be used to develop a set of management implications for the recently beginning plantation establishment in Patagonia. If followed, these implications will be useful to lower plant biodiversity loss rates in this region.

\section{Materials and Methods}

\subsection{Introduction to the Study Area and Plant Formations Observed}

Chile’s VII Region (Región Del Maule, capital Talca) and the VIII Region (Región Del Biobío, capital Concepción) together cover around $67338 \mathrm{~km}^{2}$. Around 2.7 million people inhabit this zone [53]. The area has a warm-temperate, summer dry climate, the mean annual temperature is around $12.2^{\circ} \mathrm{C}$ and precipitation is around 1330mm (Köppen-Geiger: Csb, [54]). Parallel to the Pacific lies the coastal range, followed by the central depression in the inner side of the area. Towards the east, the depression is followed by the Andes. The coastal range is made of metamorphic rock (Paleozoic age) and some intrusive volcanic rock. This basement is covered with quaternary and tertiary material transported from the Andes [55]. The coastal range is mainly covered with deciduous and sclerophyllous forests, many of which are secondary [56]. The central depression is mainly covered with shrublands of Acacia caven [57]. The zone is an area of intensive landscape transformation since the arrival of the Spanish conquerors in the $16^{\text {th }}$ century. The most intensive change in modern times, however, has taken place under the economic transformation of the Pinochet era. The area has been opened for large-scale forestry by the establishment of exotic tree plantations for economic purposes. Within this area, we assessed plant biodiversity of the following plant formations.

\subsubsection{Near-Natural Forests}

According to [11], the vegetation in the coastal range of the biodiversity hotspot of Central Chile should be separated into four large units: the deciduous Maulino forest (VII Region), the Nahuelbuta forest (VIII Region), the Valdivian evergreen forest (IX. Region) and the Chiloé evergreen forest (X region). In our study, we assessed the Maulino and Nahuelbuta forests, for an example, see Figure 1(a). Within these large units, we mainly 


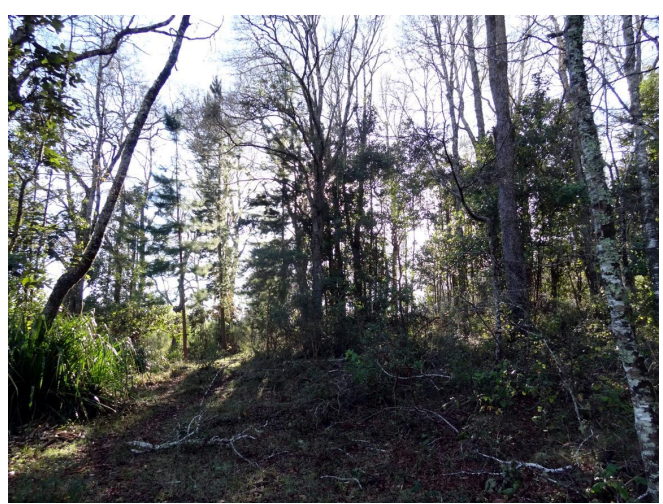

(a)

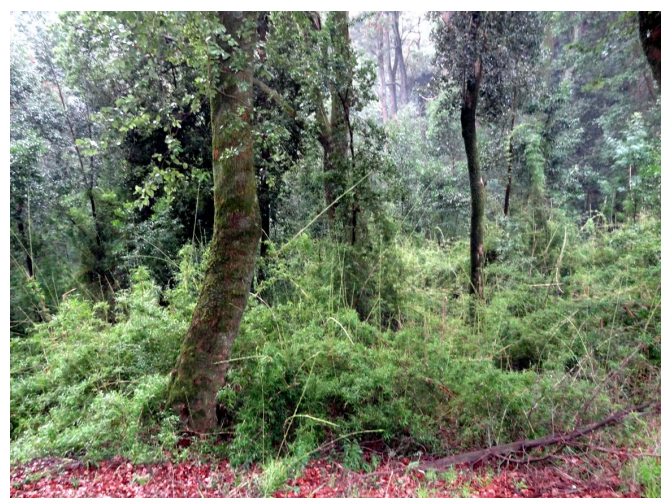

(b)

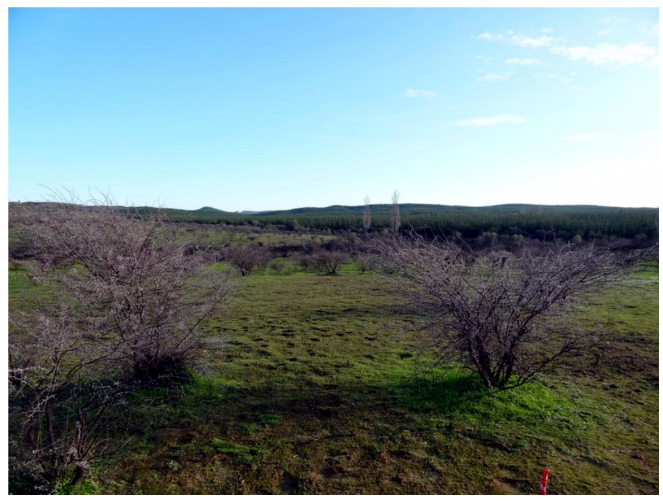

(c)

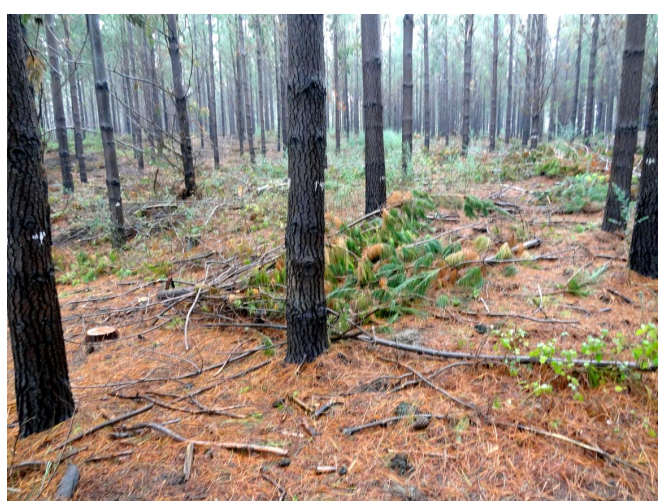

(d)

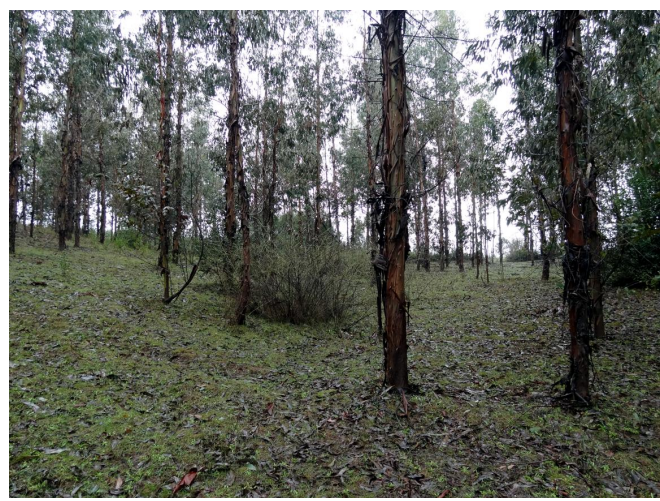

(e)

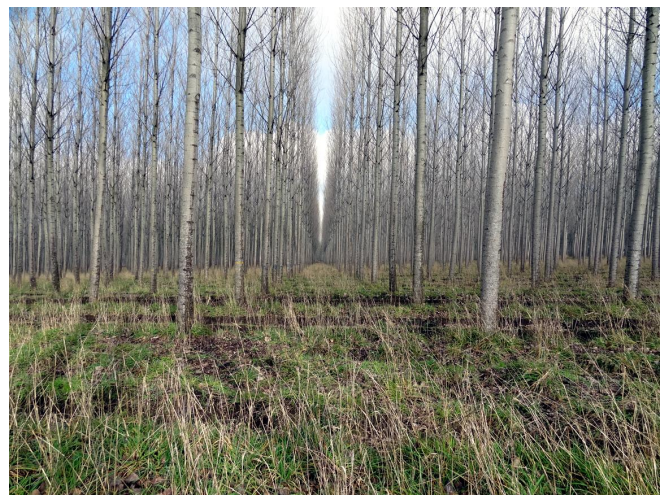

(f)

Figure 1. Examples of the studied ecosystems: (a) near-natural forest, (b) degraded forest, (c) A. cavenshrubland, (d) P. radiata plantation, (e) E. globulus plantation, (f) P. nigra plantation.

analyzed deciduous forests, dominated by Nothofagus spp., Persea lingue, Drimys winteri and Aristotelia chilensis which are a typical formation of the rather humid part of the Coastal range [58]-[60] and sclerophyllous forests dominated by Peumus boldus, Maytenus boaria, Lithreacaustica, Escallonia pulverulenta and Gevuina avellana which are typical for the rather dry part of the Coastal range [61] [62]. We furthermore assess some riparian habitats-dominated by Azara microphylla, Luma apiculata, and Rhaphithamnus spinosus - due to their special importance for plant biodiversity conservation in plantations [39]. The Maulino forest, as well as the Nahuelbuta forest are both strongly fragmented today. Outside of NPRs, like the Reserva Nacional Los Ruiles, they remain as small remnants within plantations. For our analysis, both NPRs and remnants were sampled.

\subsubsection{Degraded Forests}

Some of the forests we investigated represent degraded forests on formerly deforested areas. These forests are 
frequent in Central Chile. Degraded forests are characterized by a much larger human influence than near-natural forests. Frequently, these forests represent artificially opened or fragmented patches by anthropogenic activities. Within such patches, native or non-native shrubs like Chusqueaquila or Teline monspessulana which benefit from human disturbance frequently form dominate strata, covering large amounts of the habitat and casting shadow on the herbaceous stratum, for an example, see Figure 1(b). These effects reduce biodiversity of small shrubs and herbs. Thus, such degraded forests are expected to yield lower biodiversity values than the near-natural forests where the aforementioned shrubs only seldom form dominant strata. We investigated degraded forests of typical sclerophyllous species (Cryptocarya alba, P. boldus) and sites where plantations of E. globulus and P. radiata have been abandoned and therefore converted into degraded forests. The first type is interesting since such forests are sometimes discussed as an option to recover plant biodiversity in sustainable forms of forestry or after plantation abandonment [63], the second type is interesting since it shows plant biodiversity conditions under plantation trees without the influence of management.

\subsubsection{Acacia Caven Shrublands}

Shrublands of A. caven represent a savanna-like succession of the sclerophyllous shrublands, for an example, see Figure 1(c). The native shrublands are replaced by the $A$. caven shrublands after anthropogenic disturbance like intensive grazing or human induces fires [57]. They are composed of a single tree (A. caven) and an herbaceous stratum frequently dominated by annual species with European origin [70]. Nowadays, the $A$. caven shrublands are mainly used for extensive agroforestry [57]. The $A$. caven shrublands are considered as the most persistent formation in the central depression today. A succession from A. caven shrublands back to sclerophyllous shrublands is not to be expected [71]. The relevance of the A. caven shrublands lies in the fact that if their usage for agroforestry is given up, areas may be acquired by forestry companies and plantations will be established [72].

\subsubsection{Exotic Tree Plantations}

During the $18^{\text {th }}$ century, large areas of Central Chile suffered from initial deforestation due to Spanish and German settlers that burned areas to create space for farming. Leaving these areas without vegetation cover resulted in heavy erosion which can still be observed today. In order to prevent further erosion, plantations were established from 1900 onwards [18] [64]. For this reason, it is sometimes emphasized that plantations have mainly positive effects since they serve as erosion control [52]. However, it is ignored that since the Decree No. 701 on forest promotion of 1974, plantations are mainly established on areas formerly covered by native forests and thus not affected by erosion [11] [18] [21]-[24]. Nowadays, plantations cover the vast parts of the Coastal Range of the VII and VIII Regions. 64\% of the country's plantations are found within these regions. Plantations cover around $20 \%$ of the total area of the VII region and $33 \%$ of the VIII region. The main tree species used are $P$. radiata (84.4\% of the planted surface in the VII Region, $58.7 \%$ in the VIII Region) and E. globules (12.1\% of the planted surface in the VII Region, 38.6\% in the VIII Region) and over $75 \%$ of products are for the international market [65]. Besides, some other tree species like Populus nigra or Acacia spp. are planted (1.4\% of the planted surface in the VII Region, 2.7\% in the VIII Region) [66] [67], for examples, see Figures 1(d)-(f). Plantations in the VII and VIII region are mainly monotypic and cover large areas, frequently larger than 100 square kilometers. Trees are grown to reach around 15 years (25 at most) after which entire plantations are cut down by clear felling in a matter of days. Herbicides are applied directly after clear felling and shortly before planting the next generation of plantation trees, usually the next year [18] [64]. In the past, areas have been burned after clear felling, a practice which is abandoned today. In literature, plantations are sometimes referred to as "plantation forests" [68]. However, as [69] point out, plantations should be linguistically distinguished from forests in studies on deforestation and forest degradation; this suggestion will be followed hereafter.

\subsection{Braun-Blanquet Vegetation Assessments}

In July of 2011, a field campaign in two regions of Central Chile was carried trough (VII Región del Maule, VIII Región del Biobío). The goal of the field campaign was to assess plant biodiversity in natural and managed ecosystems of Chile's temperate zone. We assessed the species number, abundance and minimum areal according to the method of Braun-Blanquet [73]. A total of 62 vegetation relevés was assessed (13 native forest patches, seven degraded forest patches, 38 plantations and four shrublands of A. caven). Assessments were assisted by 
local vegetation experts from the University of Concepción (UdeC). No standard values from literature for the minimum areal were used since transferability to the biodiversity hotspot of Central Chile was not assumed. In order to be able to analyze $\beta$-diversity, ten coupled samples (e.g. a plantations relevé in direct vicinity to a native forests relevé) were assessed. Vegetation strata were identified and sampling was carried. According to BraunBlanquet's recommendations, we started with an area of $5 \times 5 \mathrm{~m}$, collecting and identifying all plant species present. Then, the number of species in the $5 \times 5 \mathrm{~m}$ plot was determined. The coverage of each species according to Braun-Blanquet's scale was estimated, usually by two scientist, who then agreed on a final value. Afterwards, the sampling area was sequentially increased $(10 \times 10 \mathrm{~m}, 20 \times 20 \mathrm{~m}$ etc.). The species-area curve was determined and sampling stopped when this curve reached an asymptote. The respective size of the plots for which the asymptote was reached is considered the minimum areal. The abundance-dominance method of Braun-Blanquet has been subject to some review recently [74]. For instance, it is argued that its non-metric scale makes it difficult to analyze especially with multivariate statistics [75]. However, having performed some adaptations to the abundance-dominance data, data can indeed be analyzed statistically and valid results can be achieved [76]. In order to analyze data statistically, we transformed the abundance scores into relative scores according to [77]: A species with a score of e.g. 2 has a coverage between $25 \%$ and $50 \%$. It is given a coverage value $r_{i}$ of $(0.25+0.5) / 2=0.375$. Other scores were transformed accordingly. Species with a score of + were given $r_{i}=0.025$ and species with $r$ were given $r_{i}=0.00625$. Then, the relative coverage of a species was calculated as $p_{i}=r_{i} / \sum r_{j}$ for each of the $i, j=1, \cdots, S$ species present in one relevé.

\subsection{The Plantation Biodiversity Benefit Score (PBBS)}

As [28] [78] point out it is crucial to assess biodiversity issues via standardized quantitative figures in order to enable political stakeholders to develop adequate conservation strategies. Since finding commonly acceptable standards for biodiversity is a hard task, it is proposed to use a variety of indicators to evaluate biodiversity conditions [28] [79]. One of the measures we used in order to meet these requirements is the plantation biodiversity benefit score (PBBS) proposed by [80]. The PBBS is a method specifically designed to assess the value of plantations for biodiversity conservation which consists of two components. The site scale components measures predominantly habitat diversity (e.g. presence of paddock trees, dead wood, age structure, species composition, presence of native trees), at specific sites up to 75 points can be yielded. The landscape scale component measures landscape heterogeneity and the integration of a plantation into a landscape (e.g. surrounding with native vegetation, shape of the plantation), up to 25 points can be yielded. The PBBS is the sum of both which therefore can reach a maximum value of 100 .

\subsection{Biodiversity Indices}

Several biodiversity indices are computed herein which are derived from relative abundance values. [81] proposes a new and consistent concept of defining biodiversity indices. $\alpha$-diversity ${ }^{q} D_{\alpha}$ indices are derived from the basic sum of relative abundances $\sum p_{i}^{q}$ using some exponent $q$, that is by computing ${ }^{q} D_{\alpha}=\left(\sum p_{i}^{q}\right)^{1 /(1-q)}$. From this equation, most biodiversity indices can be derived. The first index used, ${ }^{0} D_{\alpha}$, i.e. using $q=0$ equals $S$, the species richness. The second index employed herein ${ }^{2} D_{\alpha}$ uses an exponent of $q=2$. Note that with this exponent, the basic sum $\sum p_{i}^{2}$ equals the original Simpson index and ${ }^{2} D_{\alpha}=\left(\sum p_{i}^{2}\right)^{1 /(1-2)}=\left(\sum p_{i}^{2}\right)^{-1}$ equals the inverse Simpson index. Besides richness ${ }^{0} D_{\alpha}$ and inverse Simpson diversity ${ }^{2} D_{\alpha}$ an evenness index should be employed. In order to avoid biases and redundancy in the analysis, evenness should be independent of richness. [82] shows that this is only possible if evenness = diversity/richness is assumed. Thus, evenness is computed as ${ }^{2} E_{\alpha}={ }^{2} D_{\alpha} /{ }^{0} D_{\alpha}$.

For $\beta$-diversity, following [81] the Sørensen index ${ }^{q} D_{\beta}$ of species turnover between two plots $A$ and $B$ is computed. Again, ${ }^{q} D_{\beta}$ can be computed on the basis of different values for $q$. Herein, ${ }^{0} D_{\beta}$ with $q=0$ is used. Thus, differences of species relative abundances $p_{i}$ are ignored at the $\beta$-scale species presences and absences are considered for $\beta$-diversity. ${ }^{0} D_{\beta}$ is computed according to: ${ }^{0} D_{\beta}=2 \cdot{ }^{0} D_{\beta}{ }^{A \cap B} /\left({ }^{0} D_{\beta}{ }^{A}+{ }^{0} D_{\beta}{ }^{B}\right)$. In order to facilitate inter pretation of the figures, we computed the maximum $\mathrm{S} \varnothing$ rensen index $\max { }^{0} D_{\beta}$ possible for each plantation/forest couple. We did so by assuming that all species of the site with the lowers pecies number are found on the other site as well, i.e. ${ }^{0} D_{\beta}{ }^{A \cap B}=\min \left({ }^{0} D_{\beta}{ }^{A},{ }^{0} D_{\beta}{ }^{B}\right)$. We further more gave the percentage of ${ }^{0} D_{\beta}$, i.e. $\%{ }^{0} D_{\beta}=\left(100 / \max { }^{0} D_{\beta}\right) \cdot{ }^{0} D_{\beta}$. 


\subsection{Statistical Analysis}

We analyzed our data with standard statistical test procedures. Some indices of $\alpha$-diversity, like e.g. richness ${ }^{0} D_{\alpha}$, cannot be assumed to be Gaussian distributed. Instead of having to test for Gaussianness and homoscedasticity for each pair of variables, and employing a different test for each case, a consistent test procedure is employed. The nonparametric Mann-Whitney U test, which does not assume Gaussianness is employed for each pair of variables. In order to clarify the amount of reduction in ${ }^{0} D_{\alpha}$, we performed Mann-Whitney $\mathrm{U}$ test on the hypothesis that the values ${ }^{0} D_{\alpha}{ }^{A}$ of richness ${ }^{0} D_{\alpha}$ in plant formation $A$ are lower than some percentage of the values ${ }^{0} D_{\alpha}{ }^{B}$ in another plant formation $B$ (i.e. $H 1={ }^{0} D_{\alpha}{ }^{A}<f \cdot{ }^{0} D_{\alpha}{ }^{\underline{B}}$ ). We evaluate the values $f=0, \cdots, 1$ by testing the assumption several times and by determining the critical value $f_{c}$, where $H 0$ cannot be rejected anymore. $p_{c}=f_{c} \cdot 100$ is assumed to be the statistically significant percentage of reduction. Results were considered as significant on the basis of the $p \leq 0.05$ confidence level. All tests were computed using Matlab R2014a.

\subsection{Regression Analysis}

The richness data ${ }^{0} D_{\alpha}$ of plantations is assumed to partly depend on tree height. Young plantations with open canopies impose less harsh competition on understory species than plantations with higher trees and closed canopies. Thus, in younger plantations, higher ${ }^{0} D_{\alpha}$ are expected than in plantations with higher trees. In very old plantations with the highest trees, more time for ecosystem development has passed, leaving chances for more understorey species to establish. Thus, in plantations with the highest trees, richness ${ }^{0} D_{\alpha}$ is also expected to be higher. In total, these assumption theoretically motivate using $2^{\text {nd }}$ degree polynomial functions, which were used exclusively herein. The quality of the regression curved is assessed using the $R^{2}$ measure. Furthermore, a randomized procedure is employed to assess the quality of regressions. Regressions are computed $N=1000$ times on random subsets including $75 \%$ of the field data of the respective plantations. For each subset, a regression curve is produced. Then, the standard deviation $\sigma$ of the $N=1000$ regressions is computed and plotted in the graphs. All regressions were computed using the statistical package Matlab R2014a.

\section{Results}

\subsection{Alpha-Scale-Richness, Diversity, Evenness}

At first, the characteristics of the four major plant formations (near-natural forests, degraded forests, plantations and shrublands) investigated were outlined. Near-natural forests are found in NPRs and as small remnants within plantations. All three types of near-natural forests which were assessed showed a heterogeneous and diverse aspect. They were composed of three to five strata (trees, shrubs and herbaceous strata, the latter one is missing in riparian forests). For most near-natural forests we sampled the minimum areal size required to reach an asymptote in the species-area curve was $160 \times 160 \mathrm{~m}$, however, in some forests, up to $640 \times 640 \mathrm{~m}$ had to be assessed. Near-natural forests are composed of numerous herbaceous and woody plant species which grow so densely that accessibility is not assured in some places. Degraded forests also show a heterogeneous and diverse aspect. They consist of two to four vegetation strata and have a guideline minimum areal of $160 \times 160 \mathrm{~m}$. Under tree species which dissociate allelopathic compounds—e.g. C. alba and P. boldus [83]—-the richness of the herbaceous stratum can be reduced. All sites were more open than the near-natural forests and affected by human presence. The invasive bamboo species $C$. quila was found at sites were light availability and soil moisture were sufficiently high. We investigated one degraded forest of $E$. globulus and three of $P$. radiata. The sites had been established as plantations in the first place but had to remain unmanaged afterwards due to local governmental decisions. Richness within these sites was comparable to the one found under C. alba and P. boldus. However, sites were partly invaded by T. monspessulana or Rubus ulmifolius which both are far less abundant or absent in the near-natural forests. The A. caven shrublands are composed of a single tree (A. caven). Coverage of A. caven differs between them. They are composed of two to three vegetation strata and have a minimum areal of $20 \times 20$ $\mathrm{m}$. The sites were used as pastures with differing intensity. Hence, the herbaceous stratum was affected by grazing. Exotic tree plantations show a very homogeneous pattern, which is not surprising given the fact they are managed as monocultures in Central Chile. An area of $20 \times 20 \mathrm{~m}$ should be assumed as the minimum areal, though many plantations had minimum areas of only $5 \times 5 \mathrm{~m}$. Below the tree stratum, one to four shrub or herbaceous strata are found. In most cases, their coverage is very low. In the cases where coverage is higher, it is frequently composed of invasive shrubs (T. monspessulana, R. ulmifolius, Rosa rubiginosa and Acacia dealbata). 
Boxplots of the richness values ${ }^{0} D_{\alpha}$ are given in Figure 2(a), Figure 2(d) and Figure 2(g). The average richness ${ }^{0} D_{\alpha}$ of native forests is 33.3 species. Degraded forests show the second highest richness ${ }^{0} D_{\alpha}$ with 20.8 species, followed by shrublands with 13.5 species and plantations with 13.1. In the next step, the differences between richness ${ }^{0} D_{\alpha}$ of different landscape units were tested for significance according to the scheme described in Sec. 2.5. The richness ${ }^{0} D_{\alpha}$ of near-natural forests was significantly higher than the richness ${ }^{0} D_{\alpha}$ of plantations (Mann-Whitney U Test $p \approx 8.402^{-7}$ ). Furthermore, the near-natural forests hosted significantly more species than degraded forests and shrublands (Mann-Whitney U Test $p \approx 0.032 / 0.0033$ ). Other differences were found to be insignificant. Hence, a significant reduction of richness ${ }^{0} D_{\alpha}$ below exotic tree plantations could be observed.

Next, we determined the amount of reduction in ${ }^{0} D_{\alpha}$. We evaluated different values of $f$ and found $f_{c}=0.50$ to be the critical value. From there, we concluded that the richness ${ }^{0} D_{\alpha}$ below plantations was reduced by $p_{c}=45 \%$ in comparison to near-natural forest.

\subsubsection{Rarefaction Analysis}

The usage of richness ${ }^{0} D_{a}$ in biodiversity considerations is controversially debated. On the one hand, richness ${ }^{0} D_{\alpha}$ is an easy interpretable and meaningful figure which has a much more natural interpretation than e.g. higher

Richness ${ }^{0} \mathrm{D}_{\alpha}$ of Major Plant Formations

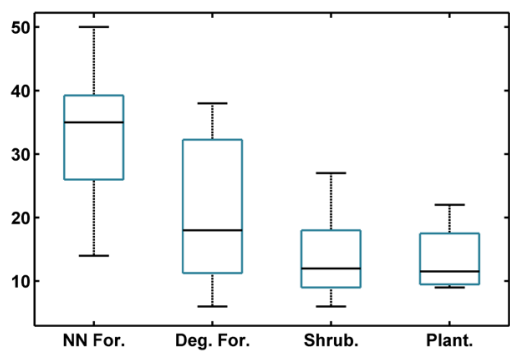

(a)

Diversity ${ }^{2} D_{\alpha}$ of Major Plant Formations

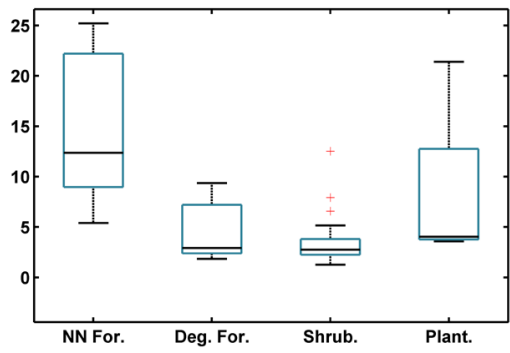

(b)

Evenness ${ }^{2} E_{\alpha}$ of Major Plant Formations

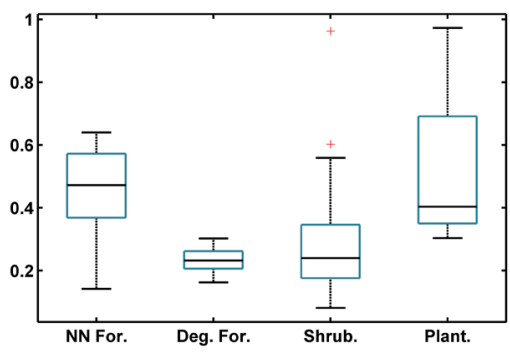

(c)
Richness ${ }^{0} D_{\alpha}$ of Near-Natural Forests

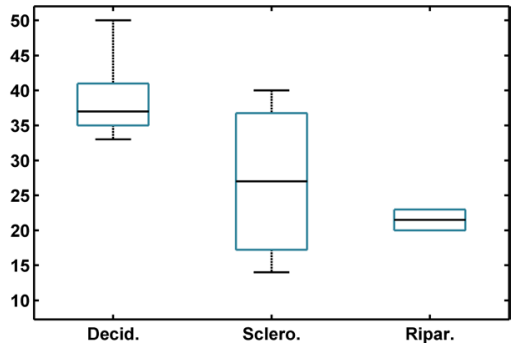

(d)

Evenness ${ }^{2} E_{\alpha}$ of Near-Natural Forests

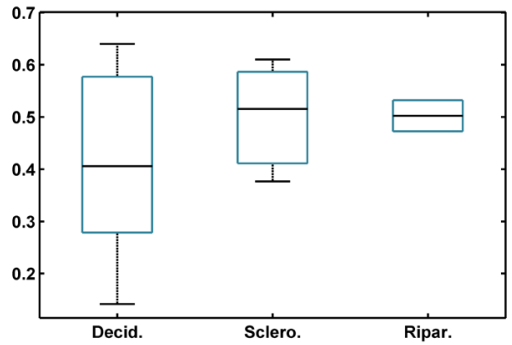

(e)

Evenness ${ }^{2} \mathrm{E}_{\alpha}$ of Near-Natural Forests

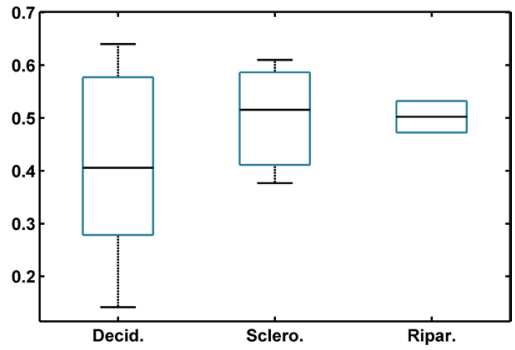

(f)

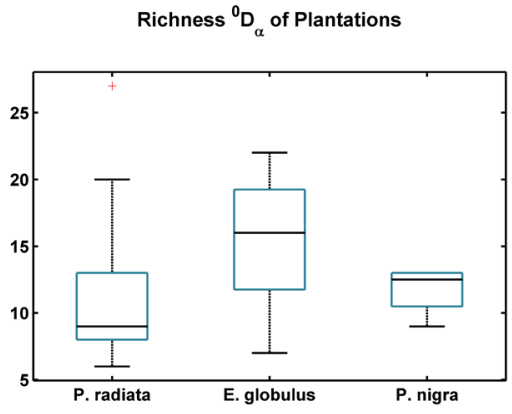

(g)

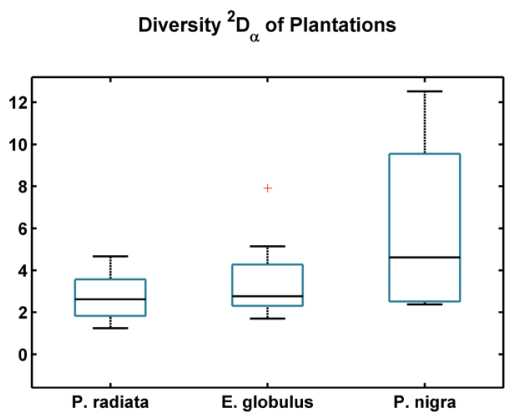

(h)

Evenness ${ }^{2} \mathrm{E}_{\alpha}$ of Plantations

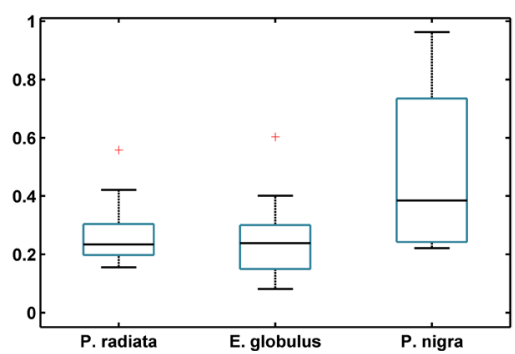

(i)

Figure 2. Boxplots of richness, diversity and evenness indices for the study systems observed. Top: richness ${ }^{0} D_{\alpha}$, center: diversity ${ }^{2} D_{\alpha}$, bottom: evenness ${ }^{2} E_{\alpha}$. Left: major plant formations, center: near-natural forests, right: plantations. Abbreviations are NN For.: near-natural forest, Deg. For.: degraded forest, Shrub.: A. caven shrubland, Plant.: commercial plantation, Decid.: deciduous forest, Sclero.: sclerophylluous forest, Ripa.: riparian forest. 
order ${ }^{a} D_{\alpha}$ values [28] [83] [84]. On the other hand, it is dependent on the sample size [30] [84] [85]. Therefore, when arguing with richness ${ }^{0} D_{\alpha}$, one should be sure to have sampled a sufficiently large area. Rarefaction analysis can be used to prove this assumption [27] [85]. We computed sample based rarefaction curves according to [85], which can be seen in Figure 3(a). In case of sufficient sampling, the curves asymptotically converge the expected richness ${ }^{0} D_{\alpha}$. However, rarefaction is sensitive to both high numbers of rare and very common species. 38 of the species ( 23\%) were found in only one relevé, 57 of the species ( 35\%) were found in up to two relevés. The plantation trees were present in all plantation relevés. Therefore, both rare and common species were present, affecting the convergence of rarefaction curves, which approximately converged for near-natural forests and plantations but not for degraded forests and shrublands.

\subsubsection{Diversity}

Near-natural forests had an average diversity index ${ }^{2} D_{\alpha}$ of 14.78 indicating that a high number of effective species is present and many of them have higher abundances. Shrublands had the second highest average index (8.25). Degraded forests had an average index value of 4.78. Plantations yield the lowest diversity index ${ }^{2} D_{\alpha}$ values with a value of 3.38, Figure 2(b), Figure 2(e), Figure 2(h). Near-natural forests had a significantly higher diversity index ${ }^{2} D_{\alpha}$ index than plantations and degraded forests did (Mann-Whitney U Test $p \approx 3.580^{-7}$ / 0.001). Other differences were found to be insignificant.

\subsubsection{Evenness}

Near-natural forest yielded the an average evenness ${ }^{2} E_{\alpha}$ value of 0.44 , shrublands yielded a value of 0.52 , followed by plantations (0.28) and degraded forests (0.23), Figure 2(c), Figure 2(f), Figure 2(i). Near-natural forests had a significantly higher evenness ${ }^{2} E_{\alpha}$ than plantations and degraded forests (Mann-Whitney U Test $p \approx$ 0.001/0.007). Furthermore, the differences between degraded forests and shrublands (Mann-Whitney U Test $p \approx$ 0.006 ) and between shrublands and plantations (Mann-Whitney U Test $p \approx 0.019$ ) were also significant. Other differences were not significant on the basis of the $p \leq 0.05$ confidence level.

\subsection{Alpha-Scale-Differences between Individual Plant Formations}

For the three different types of forests, only differences in the richness ${ }^{0} D_{\alpha}$ between mixed deciduous forests and riparian forests were significant (Mann-Whitney U Test $p \approx 0.004$ ). For the three different types of plantations, only differences in the richness ${ }^{0} D_{a}$ between $P$. radiata and $E$. globulus were significant (Mann-Whitney U Test $p \approx 0.012$ ). Since $P$. radiate covered the largest areas [67], the plantation type predominant in Central Chile obviously is far less favourable in terms of biodiversity than less frequent plantation types.

Our field experience from plantations not sampled revealed a clear ranking of richness's ${ }^{0} D_{\alpha}$, which were

Sample based Rarefaction Curves

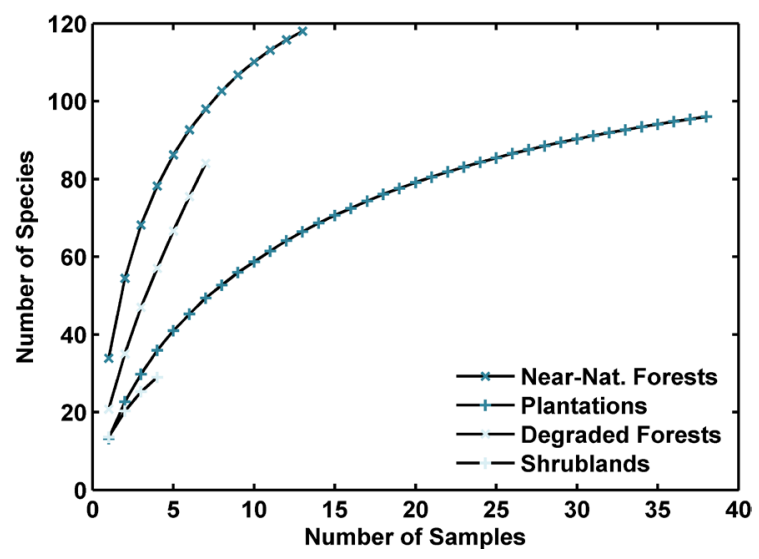

(a)
Biodiversity benefit index (PBBS) of selected plantations

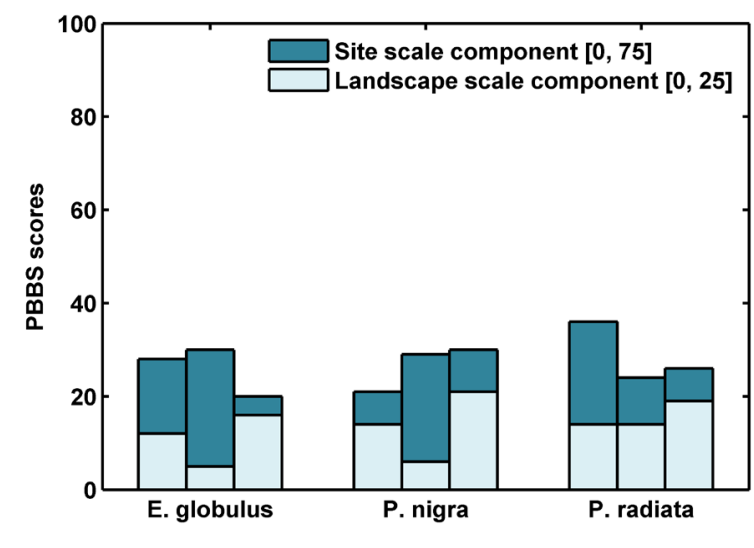

(b)

Figure 3. Left.: Sample based rarefaction curves for the studies ecosystems. Number of samples vs. number of species. Sufficiently sampled ecosystems show asymptotically converging curves. Right: Biodiversity benefit index for sampled plantations (PBBS). Site scale component and landscape scale component. 
highest below E. globulus, followed by $P$. nigra and $P$. radiata. For both diversity index ${ }^{2} D_{\alpha}$ and evenness ${ }^{2} E_{\alpha}$ values, $P$. radiata plantations yielded lower values than both $E$. globulus and $P$. nigra.

\subsection{Alpha-Scale-Relationship between Richness and Tree Height}

In the next step, the relationship between richness ${ }^{0} D_{\alpha}$ and height of the exotic trees within plantations was investigated. Experience from the field survey revealed that the number of species in the shrub and herbaceous strata is higher below young trees of $P$. radiata, E. globulus and $P$. nigra. Once the trees grow higher and close their canopy, richness ${ }^{0} D_{\alpha}$ in the strata below is reduced. In very old plantations of $P$. radiata and E. globulus, a slight rise of richness ${ }^{0} D_{\alpha}$ can be recorded. However, this observation does not account for P. nigra. In order to investigate the relationships statistically, regression curves to the plots species number against tree height were computed in Figure 4. The richness ${ }^{0} D_{\alpha}$ values of $P$. radiata and $E$. globulus were approximated via a $2^{\text {nd }}$ degree polynomial fit, due to the lower number of relevés, $P$. nigra was linearly fitted. A convincing fit can be recorded for $P$. radiate (Figure 4(a), $R^{2} \approx 0.796$ ). Richness ${ }^{0} D_{\alpha}$ is highest ${ }^{2}$ in $P$. radiata tree plantations of $2 \mathrm{~m}$ and lowest at $21 \mathrm{~m}$. A similar, but far less strong tendency can be observed for $E$. globules (Figure 4(b), $R^{2} \approx 0.274$ ). For $E$. globulus plantations richness ${ }^{0} D_{\alpha}$ is highest at $3 \mathrm{~m}$ and lowest at $17 \mathrm{~m}$. The lower determinedness is explained by the large variance in species number at medium tree heights (around $10 \mathrm{~m}$ ). Unlike $P$. radiata plantations, $E$. globulus plantations do differ much more at intermediate ages and heights. The distances between individual

Tree Height vs. Richness ${ }^{0} D_{\alpha}$ P. radiata

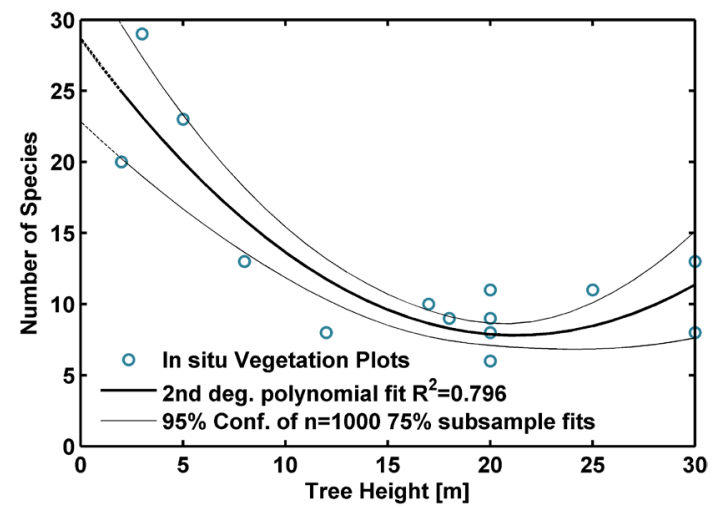

(a)

Tree Height vs. Richness ${ }^{0} D_{\alpha}$ E. globulus

Tree Height vs. Richness ${ }^{0} D_{\alpha}$ P. nigra

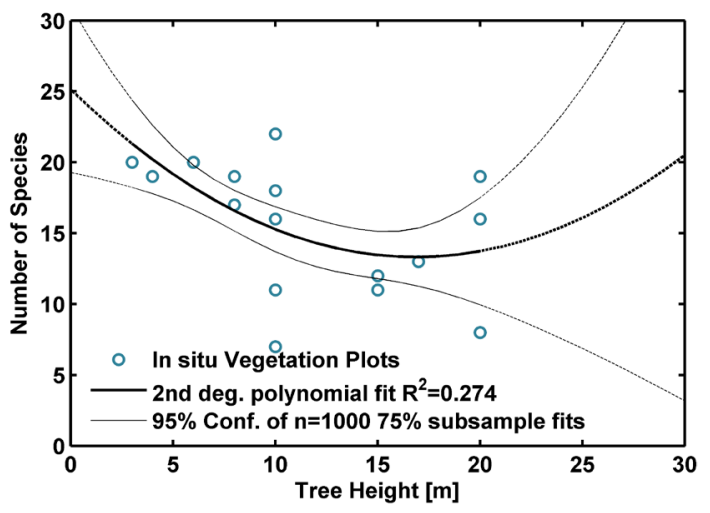

(b)

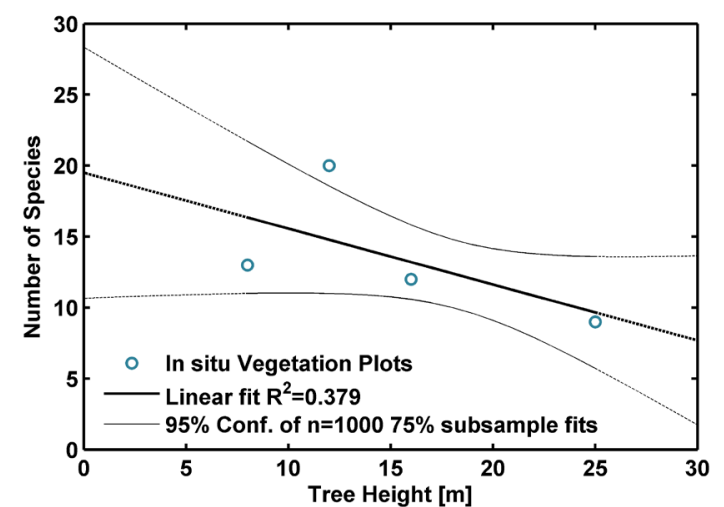

(c)

Figure 4. Regression curves between tree height and richness ${ }^{0} D_{\alpha}$ in the plantations and confidence intervals of the regressions. Dashed lines: extrapolated parts. Points: in situ assessments. Left: R. radiata, center: E. globulus, right: P. nigra.

${ }^{2}$ Decisions taken by determining the minimum and maximum values of ${ }^{0} D_{\alpha}$ and the respective tree heights within the interpolated data ranges of Figure 4. 
trees differ much more and while some sites are densely covered with pulp E. globulus, others are not. These factors seem to impose variable pressure on other species. Therefore the slight rise of the fitting curve at bigger tree heights should be interpreted cautiously. Due to the fact that $P$. nigra is far less frequently planted in Central Chile, we only took four relevés. Therefore, a linear fit instead of a $2^{\text {nd }}$ degree polynomial fit has been computed (Figure 4(c), $R^{2} \approx 0.379$ ). Richness ${ }^{0} D_{\alpha}$ is highest in plantations of $8 \mathrm{~m}$ and lowest at $25 \mathrm{~m}$. This low value is explained by the fact that herbicides had been applied to the site a couple of months before our relevé. Keeping in mind this fact, a similar tendency as for P. radiata and E. globulus was expected and confirmed by our field experience.

\subsection{Beta-Scale-Species Turnover between Forest-Plantation Couples}

In is frequently argued that plantations can contribute to biodiversity since they raise heterogeneity of landscapes, thus helping to creating diverse habitat conditions raising nichés for species [22] [30] [33] [34] [86]. If this assumption holds true, $\beta$-diversity between plantations and native species should be high; or $\beta$-similarity should be low, respectively. In the VII and VIII region of Central Chile, plantations cover vast areas and native forests are found almost exclusively as remnants within plantations, in riparian habitats along rivers or in national reserves [10] [88]. We chose ten specific sites were plantations actually appear closely linked to native forests. Five sites represented $P$. radiata plantation and five were $E$. globulus plantations. Individual figures for the index can be found in Table 1 . As can be seen, most plantation sites had a relatively high $\beta$-similarity with the native forests found nearby. The lowest value of $\%{ }^{0} D_{\beta}$ yielded was $42.9 \%$, the highest value was $100 \%$, stating that all species found in the plantation also appear in the native forest (it should be noted that the opposite is not the case). The $\%{ }^{0} D_{\beta}$ of all plantations was $64.5 \%$, indicating that most plantations show a high $\beta$-similarity with native forest. Frequently, the only species found in the plantation but not in the native forest were the plantation trees and exotic invaders like T. monspessulana, or A. dealbata. The average $\%{ }^{0} D_{\beta}$ of $P$. radiata plantations was $73.0 \%$ and $56.0 \%$ for E. globulus respectively. Thus, it appears that E. globulus contributes more to $\beta$-diversity than $P$. radiata does.

\subsection{Gamma-Scale-Relative Abundance of Exotic Species and Endemics}

As [78] point out, it is important to not only assess biodiversity on the site scale. A scale jump to the landscape scale is crucial in order to draw valid conclusions on biodiversity impacts. By then, we had analyzed and compared the site specific $\alpha$-diversity of different natural and managed plant formations and analyzed the $\beta$-diversity between them. Therefore, in a next step, we aimed to assess the plant biodiversity on the landscape scale via considerations on $\gamma$-diversity. Due to the vast extent of deforestation and plantation establishment in Central

Table 1. Comparison of near-natural forests and plantations on the $\beta$-scale, using the Sorensen ${ }^{0} D_{\beta}$ index.

\begin{tabular}{ccccccc}
\hline \multirow{2}{*}{ Plot A } & Plot B & Plant Formation A & Plant Formation B & \multicolumn{3}{c}{ Sorensen Index } \\
\cline { 6 - 7 } & & & ${ }^{0} D_{\beta}$ & $\max ^{0} D_{\beta}$ & $\%{ }^{0} D_{\beta}$ \\
\hline No. 13 & No. 15 & P. radiata plantation & Near-natural forest & 0.39 & 0.56 & 70.0 \\
No. 37 & No. 39 & P. radiata plantation & Near-natural forest & 0.37 & 0.37 & 100.0 \\
No. 24 & No. 35 & P. radiata plantation & Near-natural forest & 0.34 & 0.66 & 52.6 \\
No. 38 & No. 39 & P. radiata plantation & Near-natural forest & 0.47 & 0.73 & 65.0 \\
No. 25 & No. 28 & P. radiata plantation & Near-natural forest & 0.27 & 0.35 & 77.8 \\
No. 09 & No. 10 & E. globulus plantation & Near-natural forest & 0.48 & 0.85 & 57.1 \\
No. 27 & No. 28 & E. globulus plantation & Near-natural forest & 0.20 & 0.31 & 62.5 \\
No. 16 & No. 15 & E. globulus plantation & Near-natural forest & 0.13 & 0.31 & 42.9 \\
No. 59 & No. 56 & E. globulus plantation & Near-natural forest & 0.19 & 0.41 & 46.2 \\
No. 12 & No. 10 & E. globulus plantation & Near-natural forest & 0.61 & 0.85 & 71.4 \\
Mean & of & All plantations & & 0.35 & 0.54 & 64.5 \\
Mean & of & P. radiata plantations & & 0.36 & 0.53 & 73.0 \\
Mean & of & E. globulus plantations & & 0.32 & 0.54 & 56.0 \\
\hline
\end{tabular}


Chile, it might be argued that the landscape scale of $\gamma$-diversity is the most important one. In fact, we found 165 plant species in 63 families in total. Among them, 69 species ( 42\%) appear exclusively in non-commercial ecosystems (near-natural forests, degraded forests and shrublands). Only 9 species ( 5\%) appear exclusively in plantations. Of these, five are introduced in Chile (Cirsium vulgare, Crysanthemum coronarium, $P$. nigra, Robinia pseudoacacia, and Stellaria media). Three are native species (Lobelia tupa, Tropaeolum leptophyllum and Vicia magnifolia). The last one, Escallonia revoluta, is endemic to Chile. Among the 165 species, 35 are endemic to Chile ( 21\%), 56 species have been introduced ( 34\%). Of the 35 endemics, 34 ( 97\%) were found in at least one relevé from a natural ecosystems and $14(\sim 40 \%)$ in plantations. In general, many species-endemic or not-are rarely found. On average, species are found in only 7 relevés. Introduced species have been shown to successfully invade natural ecosystems in Chile [89] [90]. Therefore, we aimed to analyze the effects of plantations' invasive species in the next step by applying the manual of invasive plants of Chilean authorities as data basis [90]. From these manual, we selected 18 species which are expected to be found at this time of year. We calculated the relative abundances $p_{i}$ of each species mentioned therein at each relevé site. We furthermore calculated the sum of relative abundances $\sum p_{i}$ of invasive species to show to which extent each site is dominated by (potentially) invasive species. Of course, the plantation trees themselves were not included in this analysis since naturally high abundances would strongly bias results. Within plantations, 3.8 of the 18 invasive species were found on average, whereas in native forests, 3.6 invasive plants were found on average. The number of invasive species encountered within plantations was not significantly different from native forest (t-Test $p=$ 0.7348). Subsequently, we tested the difference of the sum of relative abundances $\sum p_{i}$ of the 18 invasive species for significance and revealed that $\sum p_{i}$ is significantly higher in plantations (Mann-Whitney U Test $p \approx 0.009$ ). Furthermore, we tested differences in the relative abundances pi of individual species for significance. For most species, no significant differences could be demonstrated, though T. monspessulana, Plantago lanceolata, A. dealbata and Verbascum thapsus were significantly more abundant in plantations (Mann-Whitney $\mathrm{U}$ Test $p \approx 0.0038 / 0.026 / 0.050 / 0.040$ ). Furthermore, some invasive species featured significantly higher abundance values in specific types of plantations. C. vulgare, Eschscholzia californica, Lupinus angustifolius and Taraxacum officinale were significantly more abundant in $P$. nigra plantations, while $P$. lanceolata was clearly more abundant in $P$. radiata plantations (Mann-Whitney U Test $p \approx 0.008 / 0.032 / 0.009 / 0.030 / 0.001$ ). Since Central Chile is considered an area rich in endemics [9] [91] [92], an important question is how plantations influence the abundance of endemics. We assessed this influence in the same manner as for invasive species. The information on species origin was derived from references like [93]. The average number of endemic species was 8.30 in native forests and 1.73 in exotic tree plantations. Differences were tested positively for significance. It may be argued that a reduction of relative abundances of endemic trees in plantation is straightforward. Yet, despite the intense discussions on plant biodiversity decline in plantations [10]-[20], to the knowledge of the authors, the scientific proof for the case of plants in Central Chile is still missing. Moreover, plantations managed in a more sustainable manner may maintain higher relative abundances of endemic trees. Nevertheless, in order to gain information not only on trees, but also on the understory, we analyzed the tree, shrub and herbaceous stratum separately. We computed the relative abundances of each endemic species and tested the sum of relative abundances $\sum p_{i}$ for significant differences. The sum of relative abundances $\sum p_{i}$ of endemic species in the tree and shrub strata turned out to be significantly reduced in plantations (Mann-Whitney U Test $p \approx 0.000 / 0.004$. Differences in the herbaceous stratum were insignificant (Mann-Whitney U Test $p \approx 0.018$ ). In the tree stratum, the relative abundances pi of C. alba, Myrceugenia obtusa, Nothofagus alessandrii, N. glauca and N. obliqua were significantly reduced (Mann-Whitney U Test $p \approx 0.004 / 0.017 / 0.000 / 0.020$ ). The relative abundances pi of $P$. boldus, L. caustica and Quillaja saponaria were lower, yet differences were not significant. These species are frequently found as small shrubs in the understory of plantations. In the shrub stratum, the relative abundance of Pseudopanax valdiviensis was significantly reduced (Mann-Whitney U Test $p \approx 0.018$ ). In the herbaceous stratum, the relative abundances of Hymenoglossum cruentum and Satureja multiflora were significantly reduced (Mann-Whitney U Test $p \approx 0.016 / 0.017$ ). However, note that plantations tend to be composed of less vegetation strata, the same abundance value $r_{i}$ will result in a higher relative abundance $p_{i}$.

\subsection{Plantation Biodiversity Benefits Score}

Since the PBBS measures biodiversity benefits through plantations, plantations that are claimed to promote-or at least maintain-biodiversity should yield high PBBS values (attesting good management practices to forest companies). In order to evaluate a possible beneficial influence of Chilean plantations on plant biodiversity, the 
method was applied to three sites of each tree (note that the PBBS focuses on biodiversity in general, not only plant biodiversity). All plantations observed yield rather low values, cf. Figure 3(b), (a P. radiata plantation yielded the highest value of 37). There were no significant differences between the types of plantation according to the Mann-Whitney U test ${ }^{3}$. Since the management of the plantations is very similar, they were not expected either. The landscape scale component yielded rather poor values for all plantations observed. This is explained by the fact that plantations are almost completely surrounded by other plantations. The connection to native vegetation endorsed by the PBBS is very weak.

\section{Discussion}

This study has evaluated the contribution of exotic tree plantations in Central Chile by comparing their biodiversity to forests and shrublands. It has been shown that plantations have a strong negative impact on plant biodiversity. The results indicate that plant biodiversity would benefit from diversifying plantations w.r.t. species composition. The diversity index ${ }^{2} D_{\alpha}$ values in plantations were the lowest found in the plant formations observed. The diversity index ${ }^{2} D_{\alpha}$ of near-natural forests were proven to be significantly higher. The evenness values ${ }^{2} E_{\alpha}$ of plantations were the lowest among all plant formations observed.

Rarefaction analysis was performed in order to evaluate the sufficiency of the sampling for the analyses on $\alpha$-diversity. From rarefaction, we conclude that near-natural forests and plantations are sufficiently sampled, for degraded forests and shrublands would benefit from further sampling. Therefore, conclusions based on the $\alpha$-diversity of these plant formations need to be drawn more cautiously.

Within plantations, a correlation between tree height and richness ${ }^{0} D_{\alpha}$ was substantiated. While younger plantations represent quite open habitats, light availability decreases rapidly once the canopy closes. At this age, plantations are quite similar, they differ almost exclusively with respect to pruning. However, due to the tight canopy, whether trees are pruned or not has little influence on the light availability. Furthermore, a dense layer of $P$. radiata needles is found within this particular type of plantations imposing further competitive pressure on other species. In plantations with higher trees richness ${ }^{0} D_{\alpha}$ rises slightly again. Due to the longer time of ecosystem development, habitats are more diversified leaving more niches for other species. These findings reveal that plant biodiversity would benefit from diversifying plantations w.r.t. tree ages.

In order to test the hypothesis that plantations contribute to $\beta$-diversity by raising habitat heterogeneity, the Sørensen index of ten plantation/native forest couples was computed. Although the habitat types are structurally different, Sørensen indices were rather high, attesting a high $\beta$-similarity between plantations and native forests. However, these results have to be interpreted cautiously and compared with $\alpha$-diversity. Results do not describe plantations as similar to forests w.r.t. plant biodiversity and richness ${ }^{0} D_{\alpha}$, but merely demonstrate that almost all of the rather few plant species found in plantations (low $\alpha$-diversity) also appear in native forests. Thus, plantations do not seem to contribute to local ecosystem heterogeneity and do not seem to provide habitat to additional species in the case of Central Chile as hypothesized by e.g. [22] [30] [34] [86]. Moreover, it should be kept in mind that the coastal range of Central Chile is not a diverse, small-scale pattern of plantations mixed with other habitat types. Instead, it mainly consists of vast plantations with very few sites of native forests ( $<4 \%$ of the area, own data, unpublished results). Therefore, instead of raising local habitat diversity by incorporating small-scale patches of plantations, forestry in Central Chile vastly replaces a $\alpha$-diverse habitat (native forests) by a habitat of low $\alpha$-diversity (plantations).

Concerning $\gamma$-diversity in total, most of the species are exclusively found in non-commercial ecosystems, relatively few are exclusive to plantations. Among them, many are foreign species, however, one of them is endemic to Chile. It has been shown that invasive species contribute more to species composition within plantations. Although the individual abundances of many invasive species are not significantly higher, the sum of their abundances is. This is due to the fact that some invasive species (e.g. T. monspessulana, P. lanceolata, A. dealbata or $V$. thapsus) cover large areas of the herbaceous or shrub strata below plantations. These local dominances should be monitored carefully since they can be the nucleus of invasions into native ecosystems [94] [95]. The number of endemic tree species found was only slightly lower in plantations. However, since the relative abundance of endemic species was found to be clearly reduced in plantations, it is coherent to see endemic species threatened by plantations. Above, the decline of richness ${ }^{0} D_{\alpha}$ under older plantations raises the question

${ }^{3}$ It should be kept in mind though that the results of the tests, performed to accomplish a reviewer's comment, which are based on only three plantations of each type, should not be over interpreted. 
whether endemic species will be able to survive multiple rotations. While a reduction in relative abundances of endemic trees is straightforward (intentional deforestation), a reduction in their occurrence (number of endemics) gives much concern. If plantations are to be biotopes for the survival of endemic species, these species should be found at least within the shrub stratum of plantations. Yet for many species observed, this assumption does not seem to hold. However, it should be investigated in further research whether these species are present in the seed bank below plantations.

The PBBS is proposed as a measure for biodiversity benefits of plantations. Accepting this method as valid, any plantation which promotes biodiversity should yield high values. However, all nine plantations investigated herein yield quite low values. This situation is quite typical for most plantations in Central Chile. The site scale values yielded were relatively lower. This is explained mostly by the absence of paddock trees, dead wood, and the lack of microhabitat diversity, the low variability of plantations with respect to age and density, the lack of native trees and by the fact that most plantations are monotypic. Note that the PBBS constitutes another measure to perform the scale jump from site scale to landscape scale (sensu [78]) by combining both components. Therefore, it is concluded that management practices in Central Chile do not promote biodiversity, but impair it by contrast. It should be noted that the PBBS focuses on the total biodiversity, not only on plant biodiversity. We though believe that most of the factors that are considered beneficial for the total biodiversity should apply to plant biodiversity as well (e.g. landscape heterogeneity, long rotation times, and planting of local species, site preparation and artificial hollows).

Frequently, a survival of species by the metapopulation is observed despite local extinction [31] [32]. Such a survival mechanism is coupled to landscape connectivity, but also the presence of stepping stone biotopes. There are two possible types of stepping stone biotopes which could allow for a survival of endemics metapopulations. The remnants of native forests and young plantations. Remnants of native forests indeed feature a high $\alpha$-diversity, yet distances between individual patches of these remnants can be quite large. Thus, only species with a reproductive mechanism effective over large distances are able to adapt to this situation. Some of the younger plantations we observed also had a rather high $\alpha$-diversity. However, herbicide application before planting strongly threatens saplings of native species. We therefore cannot confirm the possibility of survival of endemic species through both stepping stone biotopes. Conservation strategies for Central Chile should not be optimistically based on this option. Both degraded forests and shrublands are frequently discussed as ecosystems maintaining high biodiversity levels after restoration of areas formerly used as plantations [22] [30] [34] [87]. Results on the biodiversity of these ecosystems are ambiguous. More research should be dedicated to clarify the differences in plant biodiversity of degraded forests, shrublands and plantations. Until then, management options should not be based on the assumption that plant biodiversity can be maintained by recreating degraded forests from plantations after a couple of rotations. The data presented delineate the plant biodiversity conditions in a mainly descriptive manner.

Based on our results, the reasons for the plant biodiversity decline can be clearly attributed to the management practices in force. Obviously, plantations of $P$. radiata, E. globulus and $P$. nigra are able to suppress the regeneration of native species. Since the degraded forests of $P$. radiata and $E$. globulus show a high plant biodiversity, the management seems to be more influential than the species themselves. However, the mechanisms explaining higher competitiveness are to be clarified. Besides herbicide application, light competition seems to be another important factor in the first two decades of plantation growth given the decrease of richness ${ }^{0} D_{\alpha}$ with the tree height. In the last phase before clearfelling, richness ${ }^{0} D_{\alpha}$ slightly rises. This is explained by the fact that within older stands, the diversity of habitats rises, allowing more species to compete [87] [96] [97]. Besides the Braun-Blanquet analyses, more data will be required to explain the mechanisms of higher competitiveness.

\section{Conclusion and Outlook}

Results indicate that plantations with exotic trees put the plant biodiversity and endemism in Central Chile under great risk. Plantations of $P$. radiata show the least number of species followed by plantations of $P$. nigra and $E$. globulus. Especially for $P$. radiata, a dependency between richness and height of the plantation trees could be established. The $\beta$-similarity between plantations and native forests is high, indicating that no gain in habitat heterogeneity is achieved by plantations. Concerning $\gamma$-diversity, it is shown that plantations give habitat to less total species, and are inhabited by more invasive species and less endemic species. Applying the PBBS as a measure for favorable management practices, it is shown that management should be significantly improved 
w.r.t. to biological conservation. The homogeneity at site scale (age structure, monotypic composition, lack of natural elements and native vegetation) and the lack of connectivity with native plant formations at the landscape scale explain for the low values yielded. The tremendous decline of Chilean native forests affects the land use of entire Central Chile. Management practices are considered as the main reason for the decline of plant biodiversity in the investigated area. Since the forest companies that manage plantations in the VII and VIII region of Chile are currently expanding their business to Patagonia, a similar tendency of plant biodiversity decline has to be expected.

Finally, management implications shall be outlined. Within 35 years, the temperate zone of Central Chile has experienced rapid deforestation [10]. Plantations of exotic trees, embedded in an environmental matrix of native forests have now virtually become small remnants of native forest, embedded in an environmental matrix of plantations sometimes referred to as Green Desert [22] [28] [39] [72]. Only a few percent of the native forest vegetation have remained and almost no more space has been left for creating further plantations in forested areas. Our results attest a considerable reduction of plant biodiversity in exotic tree plantations. Related work by other authors confirm these findings [41] [42] [45]. Apparently, the main driver of plant biodiversity loss due to plantations is the poor management of plantations. Since processes of deforestations that are almost finished in the VII and VIII Region are about to begin in Patagonia — even led by the same forest companies—a further loss of plant biodiversity and endemic taxa has to be expected if similar management methods are applied. The current process of adopting Forest Stewardship Council (FSC) guidelines [65] [98] is an important first step but hardly sufficient if not substantiated and explicitly formulated into management practices [6] [99] [100]. Therefore, some important management implications shall be stated herein. First of all, harvesting by clear felling should be changed to a less intrusive form of harvesting, e.g. partial logging or gap logging with gaps smaller than $100 \mathrm{~m}$ in diameter [101]-[105]. According to literature on biodiversity conserving plantation management, a two-tiered approach would be ideal. Native forests should be conserved both within the landscape and within plantations. Research has shown that landscapes should retain at least $30 \%$ of native vegetation to prevent biodiversity decline [106]-[108]. However, in our opinion, deforestation should be strictly limited to a much lesser extent. Here, we agree with [98] that legally binding agreements for all involved parties (public and private) are strictly required. A much larger proportion of native forest remnants should be left untouched within plantations. $10 \%$ of native forest remnants within plantations are recommendable [34]. These remnants should be connected in order to enable species to form a functioning and sufficiently large metapopulation [34] [108]. Connectivity could be ensured following water courses which should be aligned by a larger buffer zone of native vegetation to prevent pollution of water supplies. Application of herbicides should be strictly limited to cases of serious pests, preventive application should be prohibited by legally binding agreements. Furthermore, plantations should be diversified w.r.t. age structure and species composition and native trees should be left in between plantations. If these management implications are ignored, Patagonia is bound to convert into an extension of the Green Desert found in the Central zone.

\section{Acknowledgements}

Acknowledgments are given to scientists of University of Concepción (UdeC), Concepción Chile for assistance during the fieldwork. These persons are Dr. Rafael Garcia, Helmuth Puschmann, Dr. Cristian Echeverria, Dr. Mauricio Aguayo, Dr. Carolina Rojas and Dr. Gunhild Hansen-Rojas.

Furthermore, the authors acknowledge the financial support for the fieldwork, granted by Ph.D. students scholarships granted by Karlsruhe Institute of Technology (KIT), Karlsruhe, which has financed the in situ sampling of this contribution.

The article processing charge was funded by the German Research Foundation (DFG) and the Albert Ludwigs University Freiburg in the funding programme Open Access Publishing.

\section{References}

[1] Fearnside, P.M. (2005) Deforestation in Brazilian Amazonia: History, Rates, and Consequences. Conservation Biology, 19, 680-688. http://dx.doi.org/10.1111/j.1523-1739.2005.00697.x

[2] Brook, B.W., Sodhi, N.S. and Ng, P.K.L. (2003) Catastrophic Extinctions Follow Deforestation in Singapore. Nature, 424, 420-426. http://dx.doi.org/10.1038/nature01795

[3] Pandit, M.K., Sodhi, N.S., Koh, L.P., Bhaskar, A. and Brook, B.W. (2007) Unreported yet Massive Deforestation 
Driving Loss of Endemic Biodiversity in Indian Himalaya. Biodiversity and Conservation, 16, 153-163. http://dx.doi.org/10.1007/s10531-006-9038-5

[4] Cowlishaw, G. (1999) Predicting the Pattern of Decline of African Primate Diversity: An Extinction Debt from Historical Deforestation. Conservation Biology, 13, 1183-1193. http://dx.doi.org/10.1046/j.1523-1739.1999.98433.x

[5] Sanchez-Cordero, V., Illoldi-Rangel, P., Linaje, M., Sarkar, S. and Peterson, A.T. (2005) Deforestation and Extant Distributions of Mexican Endemic Mammals. Biological Conservation, 126, 465-473. http://dx.doi.org/10.1016/j.biocon.2005.06.022

[6] Bennett, E.L. (2001) Timber Certification: Where Is the Voice of the Biologist? Conservation Biology, 15, 308-310. http://dx.doi.org/10.1046/j.1523-1739.2001.015002308.x

[7] Putz, F.E., Redford, K.H., Robinson, J.G., Fimbel, R. and Blate, G.M. (2000) Biodiversity Conservation in the Context of Tropical Forest Management. The World Bank, Washington DC.

[8] Forman, R.T. and Alexander, L.E. (1998) Roads and Their Major Ecological Effects. Annual Review of Ecology and Systematics, 29, 207-231. http://dx.doi.org/10.1146/annurev.ecolsys.29.1.207

[9] Myers, N., Mittermeier, R.A., Mittermeier, C.G., da Fonseca, G.A.B. and Kent, J. (2000) Biodiversity Hotspots for Conservation Priorities. Nature, 403, 853-858. http://dx.doi.org/10.1038/35002501

[10] Echeverria, C., Coomes, D., Salas, J., Rey-Benayas, J.M., Lara, A. and Newton, A. (2006) Rapid Deforestation and Forest Fragmentation of Chilean Temperate Forests. Biological Conservation, 130, 481-494. http://dx.doi.org/10.1016/j.biocon.2006.01.017

[11] Smith-Ramirez, C. (2004) The Chilean Coastal Range: A Vanishing Center of Biodiversity an Endemism in South American Temperate Rainforests. Biodiversity and Conservation, 13, 373-393. http://dx.doi.org/10.1023/B:BIOC.0000006505.67560.9f

[12] Braun, A.C., Rojas, C., Echeverria, C., Rottensteiner, F., Bähr, H.P., Niemeyer, J., Aguayo, M., Kosov, S., Hinz, S. and Weidner, U. (2014) Design of a Spectral-Spatial Pattern Recognition Framework for Risk Assessments Using Landsat Data-A Case Study in Chile. IEEE Journal of Selected Topics in Applied Earth Observations and Remote Sensing, 7, 917-928. http://dx.doi.org/10.1109/JSTARS.2013.2293421

[13] Grez, A.A., Bustamante, R.O., Simonetti, J.A. and Fahrig, L. (1998) Landscape Ecology, Deforestation and Forest Fragmentation: The Case of the Ruil Forest in Chile. In: Salinas-Chavez, E. and Middleton, J., Eds., Landscape Ecology as a Tool for Sustainable Development in Latin America, Universitario Santiago de Chile, Santiago de Chile, 32-42

[14] Bustamante, R.O. and Castor, C. (1998) The Decline of an Endangered Temperate Ecosystem: The Ruil (Nothofagus alessandrii) Forest in Central Chile. Biodiversity and Conservation, 7, 1607-1626.

[15] Altamirano, A. and Lara, A. (2010) Deforestation in Temperate Ecosystems of Pre-Andean Range of South-Central Chile. Bosque, 31, 53-64.

[16] Cisternas, M., Martinez, P., Oyarzun, C. and Debels, P. (1999) Characterization of the Replacement Processes of Native Vegetation by Forest Plantations in a Lacustrine Watershed in the Nahuelbuta Mountain Range, VIII Region, Chile. Revista Chilena de Historia Natural, 72, 661-676.

[17] Altieri, M.A. and Rojas, A. (1999) Ecological Impacts of Chile’s Neoliberal Policies, with Special Emphasis on Agroecosystems. Environment, Development and Sustainability, 1, 55-72. http://dx.doi.org/10.1023/A:1010063724280

[18] Clapp, R.A. (1995) The Unnatural History of the Monterey Pine. The Geographical Review, 85, 1-19. http://dx.doi.org/10.2307/215551

[19] Morales, F.R. (1996) La necesidad de avanzarhaciauna Historia Ecologica para Chile. Ambiente y Desarrollo, 12, 61-68.

[20] Armesto, J.J., Villagran, C. and Donoso, C. (1996) Desde la era glacial a la industrial: La historia del bosque templado chileno. Ambiente y Desarrollo, 12, 19-24.

[21] Wilson, K., Newton, A., Echeverria, C., Weston, C. and Burgman, M. (2005) A Vulnerability Analysis of the Temperate Forests of South Central Chile. Biological Conservation, 122, 9-21. http://dx.doi.org/10.1016/j.biocon.2004.06.015

[22] Guerrero, P.C. and Bustamante, R.O. (2007) Can Native Tree Species Regenerate in Pinus radiata Plantations in Chile? Evidence from Field and Laboratory Experiments. Forest Ecology and Management, 253, 97-102. http://dx.doi.org/10.1016/j.foreco.2007.07.006

[23] Guerrero, P.C. and Bustamante, R.O. (2009) Abiotic Alterations Caused by Forest Fragmentation Affect Tree Regeneration: A Shade and Drought Tolerance Gradient in the Remnants of Coastal Maulino Forest. Revista Chilena de Historia Natural, 82, 413-424.

[24] Bustamante, R.O. and Simonetti, J.A. (2005) Is Pinus radiata Invading the Native Vegetation in Central Chile? Demographic Responses in a Fragmented Forest. Biological Invasions, 7, 243-249. http://dx.doi.org/10.1007/s10530-004-0740-5 
[25] Altamirano, A., Echeverria, C., Lara, A. and Rey-Benayas, J.M. (2007) Effect of Forest Fragmentation on Vegetation Structure of Legrandia concinna (Myrtacea) Threatened Populations in South-Central Chile. Revista Chilena de Historia Natural, 80, 27-42.

[26] Langdon, B., Pauchard, A. and Aguayo, M. (2010) Pinus contorta Invasion in the Chilean Patagonia: Local Patterns in a Global Context. Biological Invasions, 12, 3961-3971. http://dx.doi.org/10.1007/s10530-010-9817-5

[27] Paritsis, J. and Aizen, M.A. (2008) Effects of Exotic Conifer Plantations on the Biodiversity of Understory Plants, Epigeal Beetles and Birds in Nothofagus dombeyi Forests. Forest Ecology and Management, 255, 1575-1583. http://dx.doi.org/10.1016/j.foreco.2007.11.015

[28] Altamirano, A., Field, R., Cayuela, L., Aplin, P., Lara, A. and Rey-Benayas, J.M. (2010) Woody Species Diversity in Temperate Andean Forests: The Need for New Conservation Strategies. Biological Conservation, 143, 2080-2091. http://dx.doi.org/10.1016/j.biocon.2010.05.016

[29] Asmüssen, M.V. and Simonetti, J.A. (2007) Can a Developing Country Like Chile Invest in Biodiversity Conservation? Environmental Conservation, 34, 183-185. http://dx.doi.org/10.1017/S0376892907004183

[30] Brockerhoff, E.G., Ecroyd, C.E. and Langer, E.R. (2001) Biodiversity in New Zealand Plantation Forests: Policy Trends, Incentives, and the State of Our Knowledge. New Zealand Journal of Forestry, 46, 31-37.

[31] Murphy, H.T. and Lovett-Doust, J. (2004) Context and Connectivity in Plant Metapopulations and Landscape Mosaics: Does the Matrix Matter? Oikos, 105, 3-14. http://dx.doi.org/10.1111/j.0030-1299.2004.12754.x

[32] Baum, K.A., Haynes, K.J., Dillemuth, F.P. and Cronin, J.T. (2004) The Matrix Enhances the Effectiveness of Corridors and Stepping Stones. Ecology, 85, 2671-2676. http://dx.doi.org/10.1890/04-0500

[33] Barlow, J., Gardner, T.A., Araujo, I.S., Avila-Pires, T.C., Bonaldo, A.B., Costa, J.E., Esposito, M.C., Ferreira, L.V., Hawes, J., Hernandez, M.I.M., Hoogmoed, M.S., Leite, R.N., Lo-Man-Hung, N.F., Malcom, J.R., Martins, M.B., Mestre, L.A.M., Miranda-Santos, R., Nunes-Gutjahr, A.L., Overal, W.L., Parry, L., Peters, S.L., Ribeiro-Junior, M.A., da Silva, M.N.F., da Silva Motta, C. and Peres, C.A. (2007) Quantifying the Biodiversity Value of Tropical Primary, Secondary, and Plantation Forests. Proceedings of the National Academy of Sciences of the United States of America, 104, 18555-18560. http://dx.doi.org/10.1073/pnas.0703333104

[34] Hartley, M.J. (2002) Rationale and Methods for Conserving Biodiversity in Plantation Forests. Forest Ecology and Management, 155, 81-95. http://dx.doi.org/10.1016/S0378-1127(01)00549-7

[35] Ferns, P.N., Cowie, R.J. and Weir, A.G. (1992) Managing Conifer Plantations for the Benefit of Granivorous Birds and Mammals. Aspects of Applied Biology, 29, 83-88.

[36] Allen, R., Platt, K. and Wiser, S. (1995) Biodiversity in New Zealand Plantations. New Zealand Forestry, 39, 26-29.

[37] Michelsen, A., Lisanework, N., Friis, I. and Holst, N. (1996) Comparisons of Understory Vegetation and Soil Fertility in Plantations and Adjacent Natural Forests in the Ethiopian Highlands. Journal of Applied Ecology, 33, 627-642. http://dx.doi.org/10.2307/2404991

[38] Chey, V.K., Holloway, J.D. and Speight, M.R. (1997) Diversity of Moths in Forest Plantations and Natural Forests in Sabah. Bulletin of Entomological Research, 87, 371-385. http://dx.doi.org/10.1017/S000748530003738X

[39] Estades, C.F. and Temple, S.A. (1999) Deciduous-Forest Bird Communities in a Fragmented Landscape Dominated by Exotic Pine Plantations. Ecological Applications, 9, 573-585. http://dx.doi.org/10.1890/1051-0761(1999)009[0573:DFBCIA]2.0.CO;2

[40] Pauchard, A., Aguayo, M., Peña, E. and Urrutia, R. (2006) Multiple Effects of Urbanization on the Biodiversity of Developing Countries: The Case of a Fast-Growing Metropolitan Area (Concepción, Chile). Biological Conservation, 127, 272-281. http://dx.doi.org/10.1016/j.biocon.2005.05.015

[41] Friend, G.R. (1982) Bird Populations in Exotic Pine Plantations and Indigenous Eucalypt Forest in Gippsland, Victoria. Emu, 82, 80-91. http://dx.doi.org/10.1071/MU9820080

[42] Freedman, B., Zelazny, V., Beaudette, D., Fleming, T., Flemming, S., Forbes, G., Gerrow, J.S., Johnson, G. and Woodley, S. (1996) Biodiversity Implications of Changes in the Quantity of Dead Organic Matter in Managed Forests. Environmental Research, 4, 238-265.

[43] Potton, C. (1994) A Public Perception of Plantation Forestry. New Zealand Forestry, 39, 2-3.

[44] Perley, C. (1994) Biodiversity, Sustainability and a Land Ethic. New Zealand Forestry, 39, 2-3.

[45] Fomegas, D.Y., Bayos, N.W. and Atayoc, J.P. (2004) Phytodiversity under Pine, (Pinus insularis) Forest Community in Tadian, Mountain Province. Proceedings: Regional Sectoral/Commodity Review, ATI-CAR, La Trinidad, 15-17 June 2004, 17-26.

[46] Vergara, P.M. and Simonetti, J.A. (2004) Avian Responses to Fragmentation of the Maulino Forest in Central Chile. Oryx, 38, 383-388. http://dx.doi.org/10.1017/S0030605304000742 
[47] Estades, C.F. (1994) Impacto de la sustitucion del bosque native por plantaciones de Pinus radiata sobre una comunidad de aves en la Octava Region de Chile. Boletin Chileno de la Ornitologia, 1, 8-14.

[48] Saavedra, B. and Simonetti, J.A. (2005) Small Mammals in Remnants of Maulino Forest and Adjacent Monterrey Pine plantations, Historia, biodiversidad y ecologia de los bosques de la cordillera de la Costa. Editorial Universitaria, Santiago de Chile.

[49] Barbosa, O. and Marquet, P.A. (2002) Effects of Forest Fragmentation on the Beetle Assemblage at the Relict Forest of Fray Jorge, Chile. Oecologia, 132, 296-306. http://dx.doi.org/10.1007/s00442-002-0951-3

[50] Peña-Cortes, F., Rebolledo, G., Hermosilla, K., Hauenstein, E., Bertran, C., Schlatter, R. and Tapia, J. (2006) Dinámica del paisaje para el período 1980-2004 en la cuencacostera del Lago Budi, Chile. Consideraciones para la conservación de sushumedales. Ecología Austral, 16, 183-196.

[51] Pawson, S.M., Brockerhoff, E.G., Watt, M.S. and Didham, R.K. (2006) Maximizing Biodiversity in Plantation Forests: Insights from Long-Term Changes in Clearfell-Sensitive Beetles in a Pinus radiata Plantation. Biological Conservation, 144, 2842-2850.

[52] Toro, J. and Gessel, S.P. (1999) Radiata Pine Plantations in Chile. New Forests, 18, 33-44. http://dx.doi.org/10.1023/A:1006597823190

[53] Instituto Nacional de Estadisticas (2002) Censo 2002: Sintesis de Resultados. Instituto Nacional de Estatisticas, Santiago de Chile.

[54] Peel, M.C., Finlayson, B.L. and McMahon, T.A. (2007) Updated World Map of the Köppen-Geiger Climate Classification. Hydrology and Earth System Sciences, 11, 1633-1644. http://dx.doi.org/10.5194/hess-11-1633-2007

[55] Veit, H. and Garleff, K. (1995) Evolucion del paisaje Cuaternario y los suelos en Chile centro-sur. In: Armesto, J.J., Villagran, C. and Arroyo, M.K., Eds., Ecologia de los bosquesnativos de Chile, Editorial Universitaria, Santiago, 363-387.

[56] Donoso, C. and Lara, A. (1995) Utilizacion de los bosquesnativos en Chile, pasado, presente y future. In: Armesto, J.J., Villagran, C. and Arroyo, M.K., Eds., Ecologia de los bosquesnativos de Chile, Editorial Universitaria, Santiago, 363-387.

[57] Ovalle, C., Avedaño, J., Aronson, J. and Del Pozo, A. (1996) Land Occupation Patterns and Vegetation Structure in the Anthropogenic Savannas (Espinales) of Central Chile. Forest Ecology and Management, 86, 129-139. http://dx.doi.org/10.1016/S0378-1127(96)03786-3

[58] Luebert, F. and Pliscoff, P. (2005) Sinopsis bioclimatica y vegetacional de Chile. Editorial Universitaria, Santiago de Chile.

[59] Amigo, J., San Martin, J. and Garcia Quintanilla, L. (2000) Estudio fitosociologico de los bosques de Nothofagus glauca (Phil.) Krasser del Centro-Sur de Chile. Phytocoenologia, 30, 193-221.

[60] Hildebrand-Vogel, R. (2002) Structure and Dynamics of Southern Chilean Natural Forests with Special Reference to Their Relation of Evergreen versus Deciduous Elements. Folia Geobotanica, 37, 107-128. http://dx.doi.org/10.1007/BF02803194

[61] Armesto, J.J. and Pickett, S. (1985) A Mechanistic Approach to the Study of Succession in the Chilean Matorral. Revista Chilena de Historia Natural, 58, 9-17.

[62] Armesto, J.J., Gutierrez, J. and Martinez, J. (1979) Las comunidades vegetales de la region mediterranea de Chile: Distribucion de especies y formas de vida en ungradiente de aridez. Medio Ambiente, 4, 62-70.

[63] Echeverria, C. and Lara, A. (2004) Growth Patterns of Secondary Nothofagus obliqua—N. alpina Forests in Southern Chile. Forest Ecology and Management, 195, 29-43. http://dx.doi.org/10.1016/j.foreco.2004.02.034

[64] Camus, P. (2003) Federico Albert: Artifice de la Gestion de los Bosques de Chile. Revista de Geografía Norte Grande, 30, 55-63.

[65] Sheppard, H.E. (1999) Certificacion forestal (II). Una opcion medioambiental de vanguardia para Chile. Ambiente y Desarrollo, 15, 54-57.

[66] CONAF (2011) Catastro de los Recursos Vegetacionales Nativos de Chile: Monitoreo de Cambios y Actualizaciones. Chilean Forest Service CONAF, Santiago de Chile.

[67] Instituto Nacional de Estadisticas (2002) Censo 2002-Sintesis de Resultados. Comision Nacinoal del XVII Censo de Poblacion y VI de Vivienda, Santiago de Chile, Chile. http://www.ine.cl/cd2002/sintesiscensal.pdf

[68] Salt, D., Lindenmayer, D. and Hobbs, R. (2004) Trees and Biodiversity: A Guide for Australian Farm Forestry. Joint Venture Agroforestry Program 2004, Australian National University, Canberra.

[69] Sasaki, N. and Putz, F.E. (2009) Critical Need for New Definitions of “Forest” and "Forest Degradation” in Global Climate Change Agreements. Conservation Letters, 2, 226-232. http://dx.doi.org/10.1111/j.1755-263X.2009.00067.x 
[70] Deil, U., Alvarez, M. and Paulini, I. (2007) Native and Non-Native Species in Annual Grassland Vegetation in Mediterranean Chile. Phytocoenologia, 37, 769-784. http://dx.doi.org/10.1127/0340-269X/2007/0037-0769

[71] Van de Vouw, W., Echeverria, C., Rey-Benayas, J.M. and Holmgren, M. (2011) Persistent Acacia Savannas Replace Mediterranean Sclerophyllous Forests in South America. Forest Ecology and Management, 262, 1100-1108. http://dx.doi.org/10.1016/j.foreco.2011.06.009

[72] Aronson, J., Del Pozo, A., Ovalle, C., Avedaño, J., Lavin, A. and Etienne, M. (1998) Land Use Changes and Conflicts in Central Chile. In: Rundel, P.W., Rizzardini, G.M. and Jaksic, F.M., Eds., Landscape Disturbance and Biodiversity in Mediterranean-Type Ecosystems, Springer, Heidelberg, 155-168. http://dx.doi.org/10.1007/978-3-662-03543-6_9

[73] Braun-Blanquet, J. (1964) Pflanzensoziologie: Grundzüge der Vegetationskunde. 3rd Edition, Springer, Berlin. http://dx.doi.org/10.1007/978-3-7091-8110-2

[74] Chytry, M., Schaminée, J.H.J. and Schwabe, A. (2011) Vegetation Survey: A New Focus for Applied Vegetation Science. Applied Vegetation Science, 14, 435-439. http://dx.doi.org/10.1111/j.1654-109X.2011.01154.X

[75] Podani, J. (2006) Braun-Blanquet’s Legacy and Data Analysis in Vegetation Science. Journal of Vegetation Science, 17, 113-117. http://dx.doi.org/10.1111/j.1654-1103.2006.tb02429.x

[76] Walker, D.A., Kuss, P., Epstein, H.E., Kade, A.N., Vonlanthen, C.M., Raynolds, M.K. and Danie F.J.A. (2011) Vegetation of Zonal Patterned-Ground Ecosystems along the North America Arctic Bioclimate Gradient. Applied Vegetation Science, 14, 440-463. http://dx.doi.org/10.1111/j.1654-109X.2011.01149.x

[77] Pellisier, V., Gallet, S. and Roze, F. (2004) Comparison of the Vegetation of Seed Bank on Hedge Banks of Different Ages in Brittany, France. Environmental Management, 34, 52-61.

[78] Spellerberg, I.F. and Sawyer, J.W.D. (1996) Standards for Biodiversity: A Proposal Based on Biodiversity Standards for Forest Plantations. Biodiversity and Conservation, 5, 447-459. http://dx.doi.org/10.1007/BF00056390

[79] Duelli, P. and Obrist, M.K. (2003) Biodiversity Indicators: The Choice of Values and Measures. Agriculture, Ecosystems \& Environment, 98, 87-98. http://dx.doi.org/10.1016/S0167-8809(03)00072-0

[80] Cawsey, E.M. and Freudenberger, D. (2008) Assessing the Biodiversity Benefits of Plantations: The Plantation Biodiversity Benefits Score. Ecological Management and Restoration, 9, 42-52. http://dx.doi.org/10.1111/j.1442-8903.2008.00386.x

[81] Tuomisto, H. (2010) A Consistent Terminology for Quantifying Species Diversity? Yes, It Does Exist. Oecologia, 164, 853-860. http://dx.doi.org/10.1007/s00442-010-1812-0

[82] Tuomisto, H. (2012) An Updated Consumer’s Guide to Evenness and Related Indices. Oikos, 121, 1203-1218. http://dx.doi.org/10.1111/j.1600-0706.2011.19897.x

[83] Verdeguer, M., Garcia-Rellan, D., Boira, H., Perez, E., Gandolfo, S. and Blazquez, M.A. (2011) Herbicidal Activity of Peumus boldus and Drimys winterii Essential Oils from Chile. Molecules, 16, 403-411. http://dx.doi.org/10.3390/molecules16010403

[84] Magurran, A.E. (2004) Measuring Biological Diversity. Blackwell Publishing, Oxford.

[85] Hurlbert, S.H. (1971) The Nonconcept of Species Diversity: A Critique and Alternative Parameters. Ecology, 52, 577586. http://dx.doi.org/10.2307/1934145

[86] Gotelli, N.J. and Colwell, R.K. (2001) Quantifying Biodiversity: Procedures and Pitfalls in the Measurement and Comparison of Species Richness. Ecology Letters, 4, 379-391. http://dx.doi.org/10.1046/j.1461-0248.2001.00230.x

[87] Lugo, A.E. (1992) Comparison of Tropical Tree Plantations with Secondary Forests of Similar Age. Ecological Monographs, 62, 1-41. http://dx.doi.org/10.2307/2937169

[88] Rojas, C., Vivanco, M., Opazo, S., Peters, S. and Constanza, V. (2011) Pre and Post Earthquake Land Use and Land Cover Identification in Concepción. In: Krisp, J.M., Meng, L., Pail, R. and Stilla, U., Eds., Earth Observation of Global Changes, Springer, Heidelberg, 223-231.

[89] Holmgren, M., Aviles, R., Sierralta, L., Segura, A.M. and Fuentes, E.R. (2010) Why Have European Herbs so Successfully Invaded the Chilean Matorral? Effects of Herbivory, Soil Nutrients and Fire. Journal of Arid Environments, 44, 197-211. http://dx.doi.org/10.1006/jare.1999.0589

[90] Figueroa, J.A., Castro, S.A., Marquet, P.A. and Jaksic, F.M. (2004) Exotic Plant Invasions to the Mediterranean Region of Chile: Causes, History and Impacts. Revista Chilena de Historia Natural, 77, 465-483.

[91] Quiroz, C.L., Pauchard, A., Marticorena, A. and Cavieres, L.A. (2009) Manual de Plantas Invasoras del Centro-Sur de Chile. Laboratorio de Invasiones Biologicas, Concepción.

[92] Muñoz-Moreira, A. (2011) Plant Geography of Chile. Springer, Heidelberg.

[93] Omarzabal, C.S. (1993) The Conservation of Biodiversity in Chile. Revista Chilena de Historia Natural, 66, $383-402$.

[94] Levine, J.M., Vila, M., Antonio, C., Dukes, J.S., Grigulis, K. and Lavorel, S. (2003) Mechanisms Underlying the Im- 
pacts of Exotic Plant Invasions. Proceedings of the Royal Society B: Biological Sciences, 270, 775-781. http://dx.doi.org/10.1098/rspb.2003.2327

[95] Hierro, J.L., Maron, J.L. and Callaway, R.M. (2005) A Biogeographical Approach to Plant Invasions: The Importance of Studying Exotics in Their Introduced and Native Range. Journal of Ecology, 93, 5-15. http://dx.doi.org/10.1111/j.0022-0477.2004.00953.x

[96] Donald, P.F., Haycock, D., Fuller, R.J., Evans, A.D. and Gough, S.J. (1998) Effects of Forest Management and Grazing on Breeding Bird Communities in Plantations with Broad-Leaved and Coniferous Trees in Western England. Biological Conservation, 85, 183-197. http://dx.doi.org/10.1016/S0006-3207(97)00114-6

[97] Keenan, R., Lamb, D., Woldring, O., Irvine, T. and Jensen, R. (1997) Restoration of Plant Biodiversity beneath Tropical Tree Plantations in Northern Australia. Forest Ecology and Management, 99, 117-131. http://dx.doi.org/10.1016/S0378-1127(97)00198-9

[98] Lara, A. (2004) Conservacion de los ecosistemas boscosos: Algunas lecciones de los ultimos 20 años. Ambiente y Desarrollo, 20, 111-115.

[99] Bennett, E.L. (2001) The Joint Effort of Timber Certification. Conservation Biology, 15, 318-319. http://dx.doi.org/10.1046/j.1523-1739.2001.015002318.x

[100] Cauley, H.A., Peters, C.M., Donovan, R.Z. and O’Connor, J.M. (2001) Forest Stewardship Council Forest Certification. Conservation Biology, 15, 311-312. http://dx.doi.org/10.1046/j.1523-1739.2001.015002311.x

[101] Neyland, M.G., Wilkinson, G.R. and Edwards, L.G. (1999) The Forestier Silvicultural Systems Trial: Alternatives to Clearfelling. Tasforests, 11, 35-48.

[102] Siira-Pietikäinen, A., Haimi, J. and Siitonen, J. (2003) Short Term Responses of Soil Macroarthropod Community to Clear Felling and Alternative Forest Regeneration Methods. Forest Ecology and Management, 172, 339-353. http://dx.doi.org/10.1016/S0378-1127(01)00811-8

[103] Baker, S.C., Grove, S.J., Forster, L., Bonham, K.J. and Bashford, D. (2009) Short-Term Responses of Ground-Active Beetles to Alternative Silvicultural Systems in the Warra Silvicultural Systems Trial, Tasmania, Australia. Forest Ecology and Management, 258, 444-459. http://dx.doi.org/10.1016/j.foreco.2009.03.044

[104] Taylor, R.J. and Haseler, M.E. (1995) Effects of Partial Logging Systems on Bird Assemblages in Tasmania. Forest Ecology and Management, 72, 131-149. http://dx.doi.org/10.1016/0378-1127(94)03470-H

[105] Lefort, P. and Grove, S. (2009) Early Responses of Birds to Clearfelling and Its Alternatives in Lowland Wet Eucalyptus Forest in Tasmania, Australia. Forest Ecology and Management, 258, 460-471. http://dx.doi.org/10.1016/j.foreco.2009.04.022

[106] Radford, J.Q., Bennett, A.F. and Cheers, G.J. (2005) Landscape-Level Thresholds of Habitat Cover for WoodlandDependent Birds. Biological Conservation, 124, 317-337.

[107] Watson, J., Freudenberger, D. and Paull, D. (2001) An Assessment of the Focal Species Approach for Conserving Birds in Variegated Landscapes in Southeastern Australia. Conservation Biology, 15, 1364-1373. http://dx.doi.org/10.1046/j.1523-1739.2001.00166.x

[108] MacIntyre, S., McIvor, J.G. and MacLeod, N.D. (2000) Principles for Sustainable Grazing in Eucalypt Woodlands: Landscape-Scale Indicators and the Search for Thresholds. In: Hale, P., Petrie, A., Maloney, D. and Sattler, P., Eds., Management for Sustainable Ecosystems, Centre for Conservation Biology, University of Queensland, Brisbane, 92-100. 
Scientific Research Publishing (SCIRP) is one of the largest Open Access journal publishers. It is currently publishing more than 200 open access, online, peer-reviewed journals covering a wide range of academic disciplines. SCIRP serves the worldwide academic communities and contributes to the progress and application of science with its publication.

Other selected journals from SCIRP are listed as below. Submit your manuscript to us via either submit@scirp.org or Online Submission Portal.
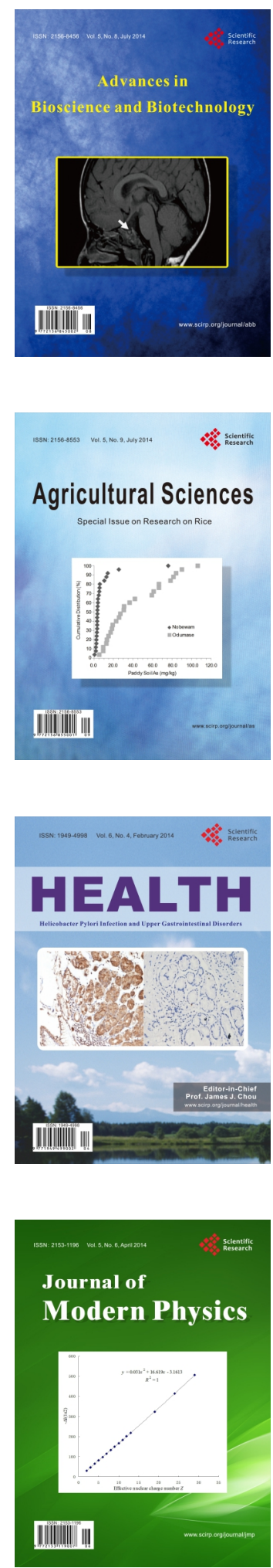
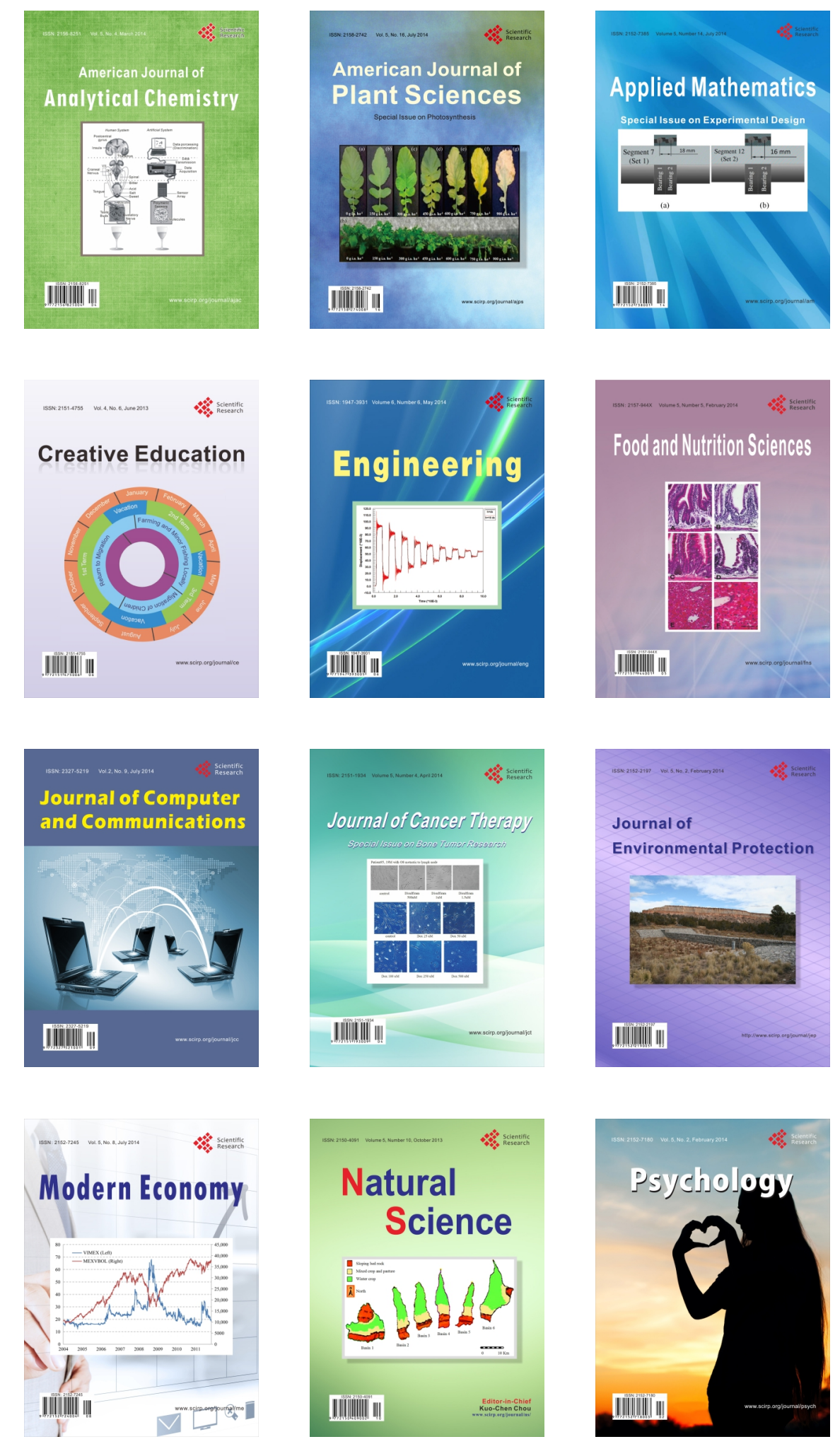